This document is the accepted manuscript version of the following article:

De Vos, M., Danine, A., Adam, L., Diliberto, S., Caballero-Calero, o., Martín-

González, M., ... Stein, N. (2020). Electrodeposition of Tin selenide from oxalate-based aqueous solution. Journal of the Electrochemical Society, $167(16), 162502$ (10 pp.). https://doi .org/10.1149/1945-7111/abcb74

\title{
Electrodeposition of tin selenide from oxalate-based aqueous solution
}

Mélanie DE VOS ${ }^{1}$, Abdelaadim DANINE $^{1}$, Laura ADAM ${ }^{1}$, Sébastien DILIBERTO ${ }^{1}$, Olga $^{3}$ CABALLERO-CALERO ${ }^{2}$, Marisol MARTÍN-GONZÁLEZ ${ }^{2}$, László PÉTER ${ }^{3}$, Attila CSÍK ${ }^{4}$, Kálmán VAD ${ }^{4}$, Laetitia PHILIPPE ${ }^{5}$, David OSENBERG ${ }^{5}$, Patricia Al-ALAM ${ }^{6}$, Gilles PERNOT $^{6}$, David LACROIX ${ }^{6}$, and Nicolas STEIN ${ }^{1 *}$

${ }^{1}$ Université de Lorraine, CNRS, IJL, F-57000 Metz, France

${ }^{2}$ Instituto de Micro y Nanotecnología, IMN-CNM, CSIC (CEI UAM+CSIC) Isaac Newton, 8 , E-28760, Tres Cantos, Madrid, Spain

${ }^{3}$ Wigner Research Centre for Physics, 1525 Budapest P.O. Box 49, Hungary

${ }^{4}$ Institute of Nuclear Research, 4001 Debrecen P.O. Box 51, Hungary

${ }^{5}$ EMPA, Laboratory of Mechanics of Materials and Nanostructures, Hungarian Academy of Sciences, Thun, Switzerland

${ }^{6}$ Université de Lorraine, CNRS, LEMTA, F-54000 Nancy, France

*Corresponding Author E-mail Address [nicolas.stein@univ-lorraine.fr]

\begin{abstract}
In this work, we report a study of the electrodeposition of SnSe. Considering the difficulty to stabilize the baths containing $\mathrm{Sn}(\mathrm{II})$ and $\mathrm{Se}(\mathrm{IV})$ precursors, we investigated the benefits of using sodium oxalate as a complexing agent. Preliminary cyclic voltammetric (CVs) experiments were performed to study the electrochemical behavior of tin and selenium redox systems within this specific electrolyte solution. The study revealed that the oxalate reagent stabilizes the bath chelating $\mathrm{Sn}$ (II) and then preventing the precipitation of $\mathrm{SnO}_{2}$. From the $\mathrm{CVs}$, a growth mechanism is proposed and a synthesis potential window is defined, in which the electrodeposition of SnSe films was investigated. Between -0.5 and $-0.6 \mathrm{~V}$ vs sat. $\mathrm{AgCl} / \mathrm{Ag}$, the deposits exhibit typical polycrystalline SnSe needle-like grains. SnSe was shown by Raman spectroscopy and the XRD patterns display an orthorhombic single-phase for this compound. Additional Mössbauer analyses confirm the presence of $\mathrm{Sn}(\mathrm{II})$, which is in good agreement with the chemical composition of SnSe films. Moreover, a cross-analysis between the methods shows also the presence of $\mathrm{SnSe}_{2}$ in minor proportion. The depth profile analyses of the samples reveal an in-depth homogeneity as well as the presence of oxygen at the layer surface.
\end{abstract}

\section{Introduction}

Polycrystalline SnSe films have long been recognized for their appropriate optical and electrical properties for photovoltaic conversion $\left[{ }^{1}\right]$. In particular, SnSe has a high absorption coefficient $\left[{ }^{2}\right]$ and behaves as a p-type semiconductor with a direct energy gap of about 1.21 $\mathrm{eV}\left[{ }^{3}\right]$. Therefore, tin selenide, composed of earth-abundant and environmentally benign elements $\left[{ }^{4}\right]$, can be advantageously used as an absorber layer in solar cells instead of CdTe or $\mathrm{CuIn}_{\mathrm{x}} \mathrm{Ga}_{(1-\mathrm{x})} \mathrm{Se}_{2}$ (CIGS), the latters being toxic and/or rare and expensive [ $\left.{ }^{5}\right]$. Moreover, thin films of tin selenide have additional potential applications such as phase-change memory $\left.{ }^{6}\right]$ or for thermoelectric materials $\left.{ }^{7}\right]$.

It should be underlined that there is a recent and important growing interest in SnSe as an alternative to conventional thermoelectric materials containing toxic and rare elements such as bismuth telluride. Its distorted rock salt structure type ( $P n m$ a space group), itself promoted by the $5 \mathrm{~s}^{2}$ lone pair of $\mathrm{Sn}$, induces anisotropic properties $\left[^{8}\right]$. Thus, its low thermal conductivity and high thermopower make it a promising material for thermoelectric devices. Indeed, Zhao et al. $\left[^{9}\right]$ reported a thermal conductivity between 0.5 and $0.7 \mathrm{~W} \cdot \mathrm{m}^{-1} \cdot \mathrm{K}^{-1}$ at room 
De Vos, M., Danine, A., Adam, L., Diliberto, S., Caballero-Calero, O., Martín-González, M., ... \& Stein, N. (2020). Electrodeposition of Tin Selenide from Oxalate-Based Aqueous Solution. Journal of the Electrochemical Society, 167(16), 162502.

Doi: 10.1149/1945-7111/abcb74

temperature and a thermopower close to $500 \mu \mathrm{V} \cdot \mathrm{K}^{-1}$ for single crystals, which results in better properties than reference materials such as $\mathrm{Bi}_{2} \mathrm{Te}_{3}$. Most of the thermoelectric materials are used in a bulk shape. However, decreasing the dimensionality is beneficial for the thermal conductivity, according to theoretical $\left[{ }^{10}\right]$ and experimental researches $\left[{ }^{11}\right]$. For thin SnSe films, Al-Alam et al. theoretically predicted the decrease of the thermal conductivity for thicknesses lower than $1 \mu \mathrm{m}\left[{ }^{12}\right]$. This trend was experimentally confirmed by Burton et al. with a thermal conductivity lower than $0.1 \mathrm{~W} \cdot \mathrm{m}^{-1} \cdot \mathrm{K}^{-1}$ and a Seebeck coefficient higher than $600 \mu \mathrm{V} \cdot \mathrm{K}^{-1}\left[{ }^{13}\right]$, which make $\mathrm{SnSe}$ thin layers a promising material for thermoelectric applications.

The conventional methods to produce SnSe films are spray pyrolysis $\left[{ }^{14}\right]$, thermal evaporation $\left[{ }^{15}\right]$, pulsed laser deposition $\left[{ }^{16}\right]$, and chemical bath deposition $\left[{ }^{17}\right]$. An alternative method is the electrodeposition technique, which combines low cost, simple processing, and a moderate growth rate, enabling good crystallinity. Electrodeposition can be performed at room temperature as well as higher temperatures in various media, aqueous, or organic solvent. By adjusting the deposition parameters, the thickness, the composition and the morphology of the deposits can be finely tuned. Thus, this synthesis method of films has successfully been applied to semiconductors $\left[{ }^{18}\right]$ and in particular for thermoelectrics $\left[{ }^{19}\right]$. Electrodeposition is of particular interest since it allows to adapt both shape and thickness to the final application, such as wearable energy harvesting $\left[{ }^{20}\right]$.

Few works involving the electrodeposition of SnSe have been reported in the literature. In his early paper devoted to the electrochemical synthesis of tin selenide, Engelken et al. $\left.{ }^{21}\right]$ emphasized the instability of the acidic chloride medium $(\mathrm{pH}=3)$ with the side reaction between $\mathrm{Sn}^{2+}$ and $\mathrm{HSeO}_{3}{ }^{-}$leading to the formation of $\mathrm{Se}^{0}$ precipitates. Geoffroy and Demopoulos $\left[{ }^{22}\right]$ have also confirmed the redox reactivity between both compounds, leading to the reductive precipitation of $\mathrm{Se}^{0}$ but also the oxidative precipitation of $\mathrm{SnO}_{2}$. Despite all these difficulties, Engelken et al. demonstrated the synthesis of polycrystalline SnSe films $\left[{ }^{21}\right]$. Later, in a similar acidic chloride-based electrolyte solution, N.R. Mathews $\left[{ }^{23}\right]$, by optimizing the applied growth potential, obtained $300 \mathrm{~nm}$ thick films with nano-porous morphology and p-type conductivity. Besides, the solution was also optimized by decreasing the $\mathrm{pH}$ to 2.8 and by introducing a large excess of $\mathrm{Sn}$ (II) over $\mathrm{Se}(\mathrm{IV})$ to maintain the bath without any precipitation, whereas the solution temperature was set to $55^{\circ} \mathrm{C}$ for a better crystallinity of the films $\left[{ }^{24}\right]$. Alternatively, to avoid the hydrolysis of $\mathrm{Sn}$ (II) into $\mathrm{Sn}_{21} \mathrm{Cl}_{16}(\mathrm{OH})_{14} \mathrm{O}_{6}\left[{ }^{22}\right]$, ethylenediaminetetraacetic acid (EDTA) was introduced in the bath as a complexing agent by Zainal et al. $\left[{ }^{25}\right]$. In the presence of EDTA, Biçer et al. $\left[{ }^{26}\right]$ have shown that the applied deposition potential influences directly the morphology and the stoichiometry of the binary tin selenide films.

Herein, focusing on the electrodeposition of $\mathrm{SnSe}$ films from an acidic and chloridecontaining aqueous solution, we suggest sodium oxalate as a bath stabilizing reagent instead of EDTA. This additive can act as a reducing agent $\left(\mathrm{E}^{0}\left(\mathrm{CO}_{2} / \mathrm{H}_{2} \mathrm{C}_{2} \mathrm{O}_{4}\right)=-0.48 \mathrm{~V}\right.$ vs. NHE) $\left.\left.{ }^{27}\right]\right)$ and a ligand for cations $\left[{ }^{28}\right]$. With this concept, recently $\mathrm{Ju}$ et al. took advantage of the chelating behavior of oxalate with $\mathrm{Sn}(\mathrm{II})$ to synthesize $\mathrm{Se} / \mathrm{SnSe}$ composite $\left[{ }^{29}\right]$. Moreover, oxalate ion is considered as readily biodegradable, as opposite to EDTA [ $\left.{ }^{30,31}\right]$ and then has the advantage of being more eco-friendly and cost-effective in comparison with EDTA. Through a preliminary electrochemical study, we investigate the morphology, the chemical composition, and the microstructure of the deposits as a function of the applied potential.

\section{Experimental features}

\section{Electrochemical study}


De Vos, M., Danine, A., Adam, L., Diliberto, S., Caballero-Calero, O., Martín-González, M., ... \& Stein, N. (2020). Electrodeposition of Tin Selenide from Oxalate-Based Aqueous Solution. Journal of the Electrochemical Society, 167(16), 162502.

Doi: 10.1149/1945-7111/abcb74

To prepare the aqueous electrolyte solution, the following steps are required by respecting the order of adding. It should be noticed that continuous stirring and bath temperature of $30^{\circ} \mathrm{C}$ need to be maintained from the addition of the first compound to the last one. Firstly, a quantity corresponding to $0.2 \mathrm{M}$ of $\mathrm{KCl}(>99 \%$, VWR) was dissolved into deionized water. Then, $0.2 \mathrm{M}$ of $\mathrm{Na}_{2} \mathrm{C}_{2} \mathrm{O}_{4}(>99.5 \%$, Alfa Aesar) was added to the bath. After the complete dissolution of oxalate salt, the $\mathrm{pH}$ was adjusted to 2.5 with $\mathrm{HCl}(\geq 37 \%$, Fluka). For the electrodeposition of $\mathrm{SnSe}$, precursors were provided in the bath by dissolving firstly $\mathrm{SnCl}_{2} \cdot 2 \mathrm{H}_{2} \mathrm{O}$ ( $\geq 98 \%$, Aldrich) and then $\mathrm{Na}_{2} \mathrm{SeO}_{3} \cdot 5 \mathrm{H}_{2} \mathrm{O}(\geq 99 \%$, Fluka). To prevent the precipitation during the solution preparation, the selenium salt was gradually incorporated. An excess of $\mathrm{Sn}(\mathrm{II})$ over $\mathrm{Se}(\mathrm{IV})$ was used in the bath, with concentrations of $20 \mathrm{mM}$ and $5 \mathrm{mM}$, respectively, according to the literature data $\left[{ }^{24,26,32,33}\right]$. This molar ratio is not derived from diffusion considerations but it prevents the potential impoverishment of tin salt in the bath due to possible hydrolysis. Chemical analyses by Inductively Coupled Plasma - Optical Emission Spectroscopy shows that the bath is stable for 1 day with no visible solid products. After storage at $30^{\circ} \mathrm{C}$ during 7 days, the tin content is mostly constant, less than $5 \%$, whereas the selenium content can be reduced up to $15 \%$ (See S1).

A three-electrode cell setup was used. A KCl-saturated $\mathrm{AgCl} / \mathrm{Ag}$ electrode and a platinum wire were used as the reference electrode and the counter-electrode, respectively. All the potential values will be given to this reference electrode throughout the present work. Concerning the working electrode, the cyclic voltammetric (CV) were performed on a glassy carbon disk electrode $\left(0.07 \mathrm{~cm}^{2}\right)$ or platinum-coated glass electrode $\left(0.025 \mathrm{~cm}^{2}\right)$. Thus, the films were deposited on platinum-coated glass specimens with a defined active surface close to $1 \mathrm{~cm}^{2}$. Platinum has the advantage to be chemically inert in comparison with silver or copper electrodes. Avoiding alloys like those observed between gold and tin, as well as keeping a good electrical conductivity favored the use of this metal as a working electrode. Before each experiment, all working electrodes were successively cleaned by sonication for 10 minutes, first in acetone then in ethanol. It should be underlined that the counter electrode was regularly cleaned by an anodic etching treatment in $1 \mathrm{M} \mathrm{NaOH}$ (Carlo Erba).

All the electrochemical measurements were carried out in deaerated electrolyte solution under a continuous argon flux, using an Autolab PGSTAT128N potentiostat/galvanostat. CV experiments were carried out with a scan rate of $10 \mathrm{mV} \cdot \mathrm{s}^{-1}$ starting from the open circuit potential (OCP). Films were synthetized by applying a fixed potential (DC mode). After each electrodeposition trial, the films were quickly immersed into $0.01 \mathrm{M} \mathrm{H}_{2} \mathrm{SO}_{4}(95-97 \%$, Sigma Aldrich), rinsed with deionized water, and then with ethanol (100\%, Carlo Erba).

\section{Characterization}

The nature of the phases present in the samples was determined by using a Bruker D8 Advance X-Ray Diffractometer (XRD) with a $\mathrm{Cu}-\mathrm{K} \alpha$ radiation source $(\lambda=1.54182 \AA)$. Raman spectrometry was carried out using a Horiba Jobin Yvon LabRam HR 800 spectrometer with a wavelength of $532 \mathrm{~nm}$. The laser power and integration time were adjusted according to the characteristics of each sample. A Tescan Vega 2SBU Scanning Electron Microscope (SEM) equipped with a Bruker nano XFlash 410-M Energy Dispersive $\mathrm{X}$-ray Spectrometer (EDS) was used to study the microstructure and evaluate the composition. Surface analyses were made at a x15000 magnification. The chemical composition was determined from EDS analysis by using the standardless ZAF correction method. For reliable results, the films were transferred and analyzed from the bottom view having a mirror-surface state. Adopting the same experimental method reported by Caballero-Calero et al. $\left[{ }^{34}\right]$, deposits were glued onto a piece of glass blade by an epoxy-based glue (from Sader ${ }^{\circledR}$ ). After 
De Vos, M., Danine, A., Adam, L., Diliberto, S., Caballero-Calero, O., Martín-González, M., ... \& Stein, N. (2020). Electrodeposition of Tin Selenide from Oxalate-Based Aqueous Solution. Journal of the Electrochemical Society, 167(16), 162502.

Doi: 10.1149/1945-7111/abcb74

at least 10 hours, the whole multilayer structure was immersed into liquid nitrogen, which enabled the separation of the deposit from the platinum substrate.

The depth profile analysis of the samples was performed by Secondary Neutral Mass Spectrometry (SNMS). The samples were also analyzed from the bottom side through the reverse sputtering method, giving a much better depth resolution at the vicinity of the substrate $\left[{ }^{35}\right]$. SNMS equipment, type INA-X, SPECS GmbH, was used in the direct bombardment mode by using $\mathrm{Ar}^{+}$ions with fairly low energy for sputtering and with a current density of $\sim 1 \mathrm{~mA} \cdot \mathrm{cm}^{-2}$. A $350 \mathrm{~V}$ sputtering potential at $100 \mathrm{kHz}$ frequency with a $80 \%$ duty cycle was applied to the samples. Post-ionized neutral particles were directed into a quadruple mass spectrometer Balzers QMA 410 by electrostatic lenses and a broadpass energy analyzer. The erosion area was confined to a circle of $3 \mathrm{~mm}$ in diameter employing a $\mathrm{Nb}$ mask. $\mathrm{A}$ profilometer (Ampbios XP-I) has been applied to analyze the depth of the sputtered crater and to calculate the sputtering rate.

${ }^{119}$ Sn Conversion Electron Mössbauer Spectrometry (CEMS) spectra were recorded by a conventional Mössbauer spectrometer from Wissel with a flowing gas $\left(96 \% \mathrm{He}, 4 \% \mathrm{CH}_{4}\right)$ proportional counter (Rikon-5) at room temperature. The velocity scale was calibrated with a ${ }^{57} \mathrm{CoRh}$ source and a metallic iron foil. The evaluation of the Mössbauer spectra was performed by the least-square fitting of lines using the Winnormos (Wissel) program. The error on all of the ${ }^{119} \mathrm{Sn}$ Mössbauer spectra was $\pm 0.1 \mathrm{~mm} \cdot \mathrm{s}^{-1}$.

\section{Results and discussion}

\section{Electrochemical behavior of the components Electrochemical stability window}

Before electrodeposition, the electrochemical behavior of the supporting electrolyte solution was investigated (Figure 1). For the bath containing only $\mathrm{KCl}$, acidified at $\mathrm{pH} 2.5$ by $\mathrm{HCl}$ and without adding $\mathrm{Na}_{2} \mathrm{C}_{2} \mathrm{O}_{4}$, the linear sweep voltammograms show the reduction reaction of $\mathrm{H}+$ into $\mathrm{H}_{2}$ (Equation 1) from $-1.66 \mathrm{~V}$ on glassy carbon electrode, whereas the onset of the solvent decomposition occurred at $-0.80 \mathrm{~V}$ on platinum electrode. The oxidation reaction of $\mathrm{H}_{2} \mathrm{O}$ into $\mathrm{O}_{2}$ (Equation 2) is observed from $1.87 \mathrm{~V}$ on glassy carbon and $1.13 \mathrm{~V}$ on platinum.

$\begin{array}{ll}2 \mathrm{H}^{+}+2 \mathrm{e}^{-} \rightarrow \mathrm{H}_{2} & \text { Equation 1 } \\ 2 \mathrm{H}_{2} \mathrm{O} \rightarrow \mathrm{O}_{2}+4 \mathrm{H}^{+}+4 \mathrm{e}^{-} & \text {Equation 2 }\end{array}$

In the presence of oxalate salt, at the same $\mathrm{pH}$, the solvent decomposition occurs at lower overpotentials for the reduction signals and for the oxidation signals respectively. The electrochemical stability window ranges from $-0.90 \mathrm{~V}$ to $0.96 \mathrm{~V}$ on glassy carbon, and from $0.32 \mathrm{~V}$ to $0.73 \mathrm{~V}$ on platinum. Thus, the use of platinum as a substrate promotes the redox reactions of the electrolyte solution.

\section{Tin-related systems}

For a better understanding of the related electrochemical system of SnSe, we first studied the individual behavior of $\mathrm{Sn}(\mathrm{II})$ and $\mathrm{Se}(\mathrm{IV})$ in the bath. In Figure 2 a, a reduction peak $\mathrm{C} 1$, attributed to the reduction of $\mathrm{Sn}$ (II) into $\mathrm{Sn}^{0}$ is observed at $-0.65 \mathrm{~V}$ (Equation 3) and a first oxidation peak $\mathrm{A} 1$, corresponding to the anodic dissolution reaction is observed at $-0.44 \mathrm{~V}$.

$\mathrm{Sn}(\mathrm{II})+2 \mathrm{e}^{-} \rightarrow \mathrm{Sn}^{0}$ Equation 3

A broad and weak anodic peak A2 is observed around $0.8 \mathrm{~V}$, which is attributed to the oxidation of $\mathrm{Sn}(\mathrm{II})$ into $\mathrm{Sn}(\mathrm{IV})$ (Equation 4). This signal can be explained by the formation of $\mathrm{SnO}_{2}$.

$\mathrm{Sn}(\mathrm{II}) \rightarrow \mathrm{Sn}(\mathrm{IV})+2 \mathrm{e}^{-}$Equation 4

Increasing the temperature up to $50{ }^{\circ} \mathrm{C}$ improves slightly the current density of the reduction reaction. Hence, it increases the amount of deposited Sn, as proven by the rise of the related dissolution anodic peak A1. Moreover, additional experiments using Levich approach show 
De Vos, M., Danine, A., Adam, L., Diliberto, S., Caballero-Calero, O., Martín-González, M., ... \& Stein, N. (2020). Electrodeposition of Tin Selenide from Oxalate-Based Aqueous Solution. Journal of the Electrochemical Society, 167(16), 162502.

Doi: 10.1149/1945-7111/abcb74

an increase of the diffusion coefficient with the temperature from $5.46 \pm 0.77 \times 10^{-6} \mathrm{~cm}^{2} \cdot \mathrm{s}^{-1}$ at room temperature to $2.89 \pm 2.32 \times 10^{-5} \mathrm{~cm}^{2} \cdot \mathrm{s}^{-1}$ at $50{ }^{\circ} \mathrm{C}$ (See S2).

Comparative CVs were realized with and without oxalate in the solution at the same $\mathrm{pH}$ (Figure $2 \mathrm{~b}$ ). All peaks are shifted in the negative direction in presence of oxalate salt, indicating a complexation between tin(II) and oxalate ions (Equation 5). By switching the direction of the potential scan to the anodic direction, a cross-over systematically appears at a potential called $\mathrm{E}_{\mathrm{CO}}$. This cross-over potential is associated with the apparent equilibrium potential of the ion/metal system $\mathrm{Sn}(\mathrm{II}) / \mathrm{Sn}^{\circ}$ in the electrolyte. In Figure $2 \mathrm{~b}$, an ECo value of $0.46 \mathrm{~V}$ vs sat. $\mathrm{AgCl} / \mathrm{Ag}^{\circ}$ is recorded in absence of oxalate salt. This value has to be compared with the standard redox potential of $-0.34 \mathrm{~V}$ vs sat. $\mathrm{AgCl} / \mathrm{Ag}^{\circ}$ of $\mathrm{Sn}^{2+} / \mathrm{Sn}^{0}\left[{ }^{24}{ }^{36}\right.$, the difference is due to the activity of the cation and its possible complexation with chloride. A cathodic shift of the $E_{\mathrm{CO}}$ value is observed from $-0.46 \mathrm{~V}$ to $-0.6 \mathrm{~V}$ without and with oxalate salt respectively. This observation unambiguously indicates that the cation $\mathrm{Sn}(\mathrm{II})$ is complexed in presence of oxalate salt. From the literature data $\left[{ }^{29}\right]$ and by taking into account the acidic properties of oxalate, we suggest the formation of a complex according to the following equation :

$\mathrm{Sn}(\mathrm{II})+\mathrm{HC}_{2} \mathrm{O}_{4}^{-} \rightarrow \mathrm{SnC}_{2} \mathrm{O}_{4}+\mathrm{H}^{+}$Equation 5

This hypothesis is in agreement with the fact that, in absence of oxalate salt, the electrolyte solution remains cloudy, probably due to the oxidation of tin with dissolved oxygen resulting in the precipitation of $\mathrm{SnO}_{2}$ (Equation 6).

$2 \mathrm{Sn}(\mathrm{II})+2 \mathrm{H}_{2} \mathrm{O}+\mathrm{O}_{2} \rightarrow 2 \mathrm{SnO}_{2}+4 \mathrm{H}^{+}$Equation 6

It should be pointed out that, even if the bath is stabilized in the presence of oxalate, this effect is time-limited. Indeed, signal occurrences due to tin completely disappear for a two days old bath (Figure $2 \mathrm{c}$ ). The influence of the substrate is highlighted in Figure $2 \mathrm{~d}$, which displays the comparative CVs of the solution with platinum and glassy carbon as the working electrode. On platinum, the reduction peak $\mathrm{C} 1$ has a larger current density, in term of absolute value and its position is slightly shifted to $-0.63 \mathrm{~V}$ instead of $-0.68 \mathrm{~V}$. We can note an additional reduction peak $\mathrm{C} 0$ at $-0.54 \mathrm{~V}$, preceding the bulk deposition ( $\mathrm{C} 1$ peak) This peak could correspond to the Underpotential Deposition (UPD) of $\mathrm{Sn}$ (II) on Pt, similarly to the works of Biçer et al. $\left.{ }^{26}\right]$ on gold. Another hypothesis is the reduction of the solvent as suggested by the study of the electrochemical stability window (Figure 1).

\section{Selenium-related systems}

Similar experiments were done with selenium salt $\left(\mathrm{Na}_{2} \mathrm{SeO}_{3}\right)$, where the typical voltammogram at room temperature (Figure 3 a) exhibits one broad cathodic peak C2' located at $-0.71 \mathrm{~V}$. By increasing the solution's temperature from room temperature to $50{ }^{\circ} \mathrm{C}$, a shoulder is detected, suggesting an additional peak $\mathrm{C} 1$ ' at $-0.62 \mathrm{~V}$. The two cathodic peaks are attributed to the successive reductions of $\mathrm{Se}(\mathrm{IV})$ into $\mathrm{Se}^{0}$ according to the Equation 7 and of $\mathrm{Se}^{0}$ into $\mathrm{Se}(-\mathrm{II})$, generating $\mathrm{H}_{2} \mathrm{Se}$ gas (Equation 8). The increase of the cathodic peaks with the temperature is explained by the increase of the diffusion coefficient of $\mathrm{Se}(\mathrm{IV})$, from $1.15 \pm$ $0.04 \times 10^{-6} \mathrm{~cm}^{2} \cdot \mathrm{s}^{-1}$ at room temperature up to $4.29 \pm 4.07 \times 10^{-6} \mathrm{~cm}^{2} \cdot \mathrm{s}^{-1}$ at $50{ }^{\circ} \mathrm{C}(\mathrm{see} \mathrm{S} 2)$.

At room temperature, the reduction step ( $\mathrm{C}^{\prime}$ ) involves the uptake of 6 electrons without the separation of intermediate steps, and hence, solid Se does not appear (Equation 7). We can note that, by considering its acidic properties, $\mathrm{Se}(\mathrm{IV})$ is protonated under the form $\mathrm{H}_{2} \mathrm{SeO}_{3}$.

$$
\begin{array}{ll}
\mathrm{H}_{2} \mathrm{SeO}_{3}+4 \mathrm{H}^{+}+4 \mathrm{e}^{-} \rightarrow \mathrm{Se}+3 \mathrm{H}_{2} \mathrm{O} & \text { Equation 7 } \\
\mathrm{Se}^{0}+2 \mathrm{H}^{+}+2 e^{-} \rightarrow \mathrm{H}_{2} \mathrm{Se} & \text { Equation 8 }
\end{array}
$$


De Vos, M., Danine, A., Adam, L., Diliberto, S., Caballero-Calero, O., Martín-González, M., ... \& Stein, N. (2020). Electrodeposition of Tin Selenide from Oxalate-Based Aqueous Solution. Journal of the Electrochemical Society, 167(16), 162502.

Doi: 10.1149/1945-7111/abcb74

The apparent equilibrium potential of the selenium system $\left(\mathrm{H}_{2} \mathrm{SeO}_{3} / \mathrm{Se}^{\circ}\right)$ cannot be estimated since no anodic stripping peak is recorded. From the literature data ${ }^{36}$, the value of the standard redox potential of the following reaction is $-0.57 \mathrm{~V}$ vs sat. $\mathrm{AgCl} / \mathrm{Ag}^{\circ}$.

$\mathrm{SeO}_{3}^{2-}+3 \mathrm{H}_{2} \mathrm{O}+4 \mathrm{e}^{-} \rightarrow \mathrm{Se}+6 \mathrm{OH}^{-}$Equation 9

This value is in good agreement with the position of the $\mathrm{C} 1$ ' peak, attributed to the deposition of selenium. The position of the $\mathrm{C} 2$ ' has to be compared with the value of $-0.60 \mathrm{~V}$ vs sat. $\mathrm{AgCl} / \mathrm{Ag}^{\circ}$ of the standard redox potential $\left[{ }^{37}\right]$ of the reaction 8 .

Whatever the solution temperature and the chemical composition, no anodic dissolution of $\mathrm{Se}^{0}$ is observed. By considering the results in the literature, various and opposed electrochemical behaviors are observed, depending on the working electrode. Thus, on single-crystalline gold (111) $\left.{ }^{38}\right]$ or (100) $\left[{ }^{39}\right]$, distinct oxidation peaks are observed due to the anodic dissolution of bulk Se deposit and UPD Se. In such experimental conditions, trigonal crystalline films are obtained. On the other hand, an irreversible reduction of Se(IV) is observed, for example, on polycrystalline gold $\left[{ }^{40}\right]$, glassy carbon $\left[{ }^{41}\right]$, or PtO-free platinum electrode $\left[{ }^{42}\right]$.

Taking into account the work of $J u$ et al. $\left[{ }^{29}\right]$, we exclude a complexation of selenium by oxalate, which preferentially complexes tin. This assumption is reinforced by comparing the electrochemical behavior of $\mathrm{Se}(\mathrm{IV})$ with and without oxalate salt (Figure $3 \mathrm{~b}$ ) since no cathodic shift is observed. However, the peaks are attenuated and indistinct in the absence of oxalate.

On platinum (Figure $3 \mathrm{c}$ ), the intensities of cathodic peaks $\mathrm{C} 1$ ' and $\mathrm{C} 2$ ' are higher than on glassy carbon and the signal becomes noisy from $-0.7 \mathrm{~V}$. This observation is linked to the hydrogen evolution reaction (Equation 1), which occurs on platinum at lower overpotentials, leading to noisy cyclic voltammetry curves. However, we can guess the presence of the peak $\mathrm{C} 2$ ' at $-0.72 \mathrm{~V}$, which is close to the peak obtained on glassy carbon.

These experiments suggest that the presence of oxalate in the electrolyte solution, the use of the platinum electrode, and a solution temperature of $50{ }^{\circ} \mathrm{C}$ have a beneficial impact on the stability of the bath and the cathodic behavior of the single elements $\mathrm{Sn}$ (II) and $\mathrm{Se}(\mathrm{IV})$. Therefore, these experimental parameters were retained to investigate the $\mathrm{SnSe}$ electrochemical system.

\section{Tin Selenide-related systems}

To compare with the voltammetric results achieved for Sn and Se, the electrolyte solution was studied including both electroactive species on platinum (Figure 4 a). Cyclic voltammetric experiments were performed between $-0.75 \mathrm{~V}$ and $1 \mathrm{~V}$. A first reduction peak $\mathrm{C} 0$ " is observed at $-0.52 \mathrm{~V}$, followed by a sharp and noisy peak $\mathrm{C} 1$ " from $-0.6 \mathrm{~V}$. In the anodic return part, a first oxidation peak A1" is noticed around $-0.5 \mathrm{~V}$, and two other oxidation peaks A2" and A3" are visible at $0.1 \mathrm{~V}$ and $0.84 \mathrm{~V}$ respectively. By reducing the scanned potentials range to $-0.55 \mathrm{~V} / 1 \mathrm{~V}$, we can deduce that $\mathrm{A} 1$ " is linked to $\mathrm{C} 1$ ". Moreover, the positions of both peaks are similar to those of $\mathrm{C} 1$ and $\mathrm{A} 1$ of tin(II) on platinum (Figure $2 \mathrm{~d}$ ). Also, the anodic peak A1" is asymmetric, which is characteristic of the anodic dissolution process of a layer of limited thickness (stripping peak). Therefore, both peaks C1" and A1" can be surely assigned to the metallic tin system according to Equation 3.

On the other hand, the assignment of the wide cathodic peak $\mathrm{C} 0$ " is not obvious. In comparison with the individual behaviors of $\mathrm{Sn}$ (II) and Se(IV), the signal may be due to the UPD of $\mathrm{Sn}^{0}$ and/or the bulk deposition of $\mathrm{Se}^{0}$, respectively. We can note that the cathodic signal becomes noisy just after the peak $\mathrm{C} 0$ ". This phenomenon can be attributed to gas evolution at the electrode, with the possibility of the formation of $\mathrm{H}_{2} \mathrm{Se}$ according to Equation 8 .

Therefore, in this potential range around C0", the formation of SnSe is expected according two possibilities. Firstly we can consider the reduction of $\mathrm{Se}(\mathrm{IV})$ to $\mathrm{Se}(-\mathrm{II})$ in the presence of 
De Vos, M., Danine, A., Adam, L., Diliberto, S., Caballero-Calero, O., Martín-González, M., ... \& Stein, N. (2020). Electrodeposition of Tin Selenide from Oxalate-Based Aqueous Solution. Journal of the Electrochemical Society, 167(16), 162502.

Doi: 10.1149/1945-7111/abcb74

$\mathrm{Sn}(\mathrm{II})$ (Equation 10), as suggested by Ham et al. $\left[{ }^{43}\right]$. In other words, we suggest a mechanism, where the generation of SnSe involves the reduction of $\mathrm{Se}(\mathrm{IV})$ to $\mathrm{Se}(-\mathrm{II})$, without reduction of tin. Then, the binary compound is obtained by the precipitation of $\mathrm{SnSe}$.

$\mathrm{SnC}_{2} \mathrm{O}_{4}+\mathrm{H}_{2} \mathrm{SeO}_{3}+6 e^{-}+5 \mathrm{H}^{+} \rightarrow \mathrm{SnSe}+\mathrm{HC}_{2} \mathrm{O}_{4}^{-}+3 \mathrm{H}_{2} \mathrm{O}$ Equation 10

Another possibility could be a two-step deposition mechanism, in a similar way of telluride compounds such as $\mathrm{Bi}_{2} \mathrm{Te}_{3}\left[{ }^{44}\right]$. The first step would be the reduction of $\mathrm{Se}(\mathrm{IV})$ into $\mathrm{Se}^{\circ}$ according the Equation 7, triggering the reduction of $\mathrm{Sn}(\mathrm{II})$ as given in the Equation 11.

\section{$\mathrm{SnC}_{2} \mathrm{O}_{4}+\mathrm{Se}+2 e^{-} \rightarrow \mathrm{SnSe}+\mathrm{C}_{2} \mathrm{O}_{4}^{2-} \quad$ Equation 11}

Whatever the deposition mechanism, SnSe should be obtained in this potential range.

In Figure $4 \mathrm{~b}$, further CVs were carried out in the limited potential range of $-0.55 \mathrm{~V}$ to $1 \mathrm{~V}$ with pauses at $-0.55 \mathrm{~V}$ during $30 \mathrm{~s}$ and $60 \mathrm{~s}$. No differences were detected concerning the anodic peaks A2" and A3", in terms of position and intensity. Therefore, they cannot be assigned to C0" by considering a bulk deposition but they should be due to a surface limited cathodic reaction.

Nevertheless, deposits at fixed applied potentials were conducted for a better understanding and the results are discussed below. Considering the cyclic voltammetry results, the potential domain of interest for the electrodeposition of SnSe films should be from -0.5 to $-0.6 \mathrm{~V}$.

\section{SEM-EDS analyses}

Figure 5 gathers typical surface images of the samples obtained for different fixed potentials from $-0.4 \mathrm{~V}$ to $-0.7 \mathrm{~V}$. Various microstructure are observed according to the applied potential.

By applying a potential of $-0.45 \mathrm{~V}$ and below, the layers exhibit an inhomogeneous surface morphology, as shown on the SEM images in Figure 5 a and Figure $5 \mathrm{~b}$. Moreover, the shapes of the grains do not correspond to the typical well-defined needle-like morphology of the SnSe deposits $\left[{ }^{26,45}\right]$.

The samples deposited at $-0.5 \mathrm{~V}$ cover the substrate only partially (Figure $5 \mathrm{c}$ ), whereas those made at $-0.55 \mathrm{~V}$ completely cover the substrate (Figure $5 \mathrm{~d}$ ). Aggregates can be found whatever the potential but the deposits made at $-0.6 \mathrm{~V}$ exhibit the biggest aggregates (Figure 5 e). In the potential windows $-0.5 \mathrm{~V} /-0.6 \mathrm{~V}$, all samples exhibit needle-like grains (Figure $5 \mathrm{c}$, $5 \mathrm{~d}$ and $5 \mathrm{e}$ ), as observed by Biçer and Sisman for electrodeposited films in presence of EDTA $\left[{ }^{26}\right]$ as well as films made by evaporation $\left[{ }^{45}\right]$.

The deposits at $-0.7 \mathrm{~V}$ provide powdery samples (Figure $5 \mathrm{f}$ ), with a strong adherence between tin and platinum. Therefore, the transfer process is often difficult, due to the presence of residual platinum on the samples. Moreover, the non-compact and powdery aspect of the films at this potential could indicate a side reaction with the generation of gas such as $\mathrm{H}_{2}$ and/or $\mathrm{H}_{2} \mathrm{Se}$. We have observed that a red deposit can be occasionally present, corresponding to the amorphous phase of selenium ${ }^{[20]}$. The produced $\mathrm{H}_{2} \mathrm{Se}$ at the electrode can react with $\mathrm{H}_{2} \mathrm{SeO}_{3}$ in the solution and leads to the formation of $\mathrm{Se}^{0}$ (Equation 12) :

$\mathrm{H}_{2} \mathrm{SeO}_{3}+2 \mathrm{H}_{2} \mathrm{Se} \rightarrow 3 \mathrm{Se}+3 \mathrm{H}_{2} \mathrm{O}$ Equation 12

From these images, it appears that the samples deposited in the potential windows $-0.5 \mathrm{~V} /-0.6$ $\mathrm{V}$ exhibit homogeneous surfaces, with the expected microstructure of SnSe. Therefore, cross views analyses were carried out on these samples (Figure 6). They have a thickness close to 2 $\mu \mathrm{m}$ with a fixed charge of $-12.7 \mathrm{C} \cdot \mathrm{cm}^{-2}$. Considering the Faraday law (Equation 13), we expected to have a thickness of $7 \mu \mathrm{m}$.

$e=\frac{Q M}{-n F \rho A} \quad$ Equation 13 
De Vos, M., Danine, A., Adam, L., Diliberto, S., Caballero-Calero, O., Martín-González, M., ... \& Stein, N. (2020). Electrodeposition of Tin Selenide from Oxalate-Based Aqueous Solution. Journal of the Electrochemical Society, 167(16), 162502.

Doi: 10.1149/1945-7111/abcb74

where $e, Q, M, n, F, \rho$, and $A$ are respectively the theoretical thickness, the charge, the molar weight, the number of exchanged electrons, the Faraday constant, the density, and the surface area of the electrode. This leads to a Faradaic yield of only $28.6 \%$, which can be explained by the side reactions such as the hydrogen evolution reaction (Equation 1) and the formation of $\mathrm{H}_{2} \mathrm{Se}$ (Equation 8).

The distinctive observed morphologies for the different applied potentials are correlated to their specific growth mode. With a fixed charge of $-12.7 \mathrm{C} \cdot \mathrm{cm}^{-2}$, the growth duration decreases from $26000 \mathrm{~s}$ at $-0.4 \mathrm{~V}$ down to $2620 \mathrm{~s}$ at $-0.7 \mathrm{~V}$ (see S3). Between $-0.5 \mathrm{~V}$ and 0.6 $\mathrm{V}$, a quasi-stable growth duration around $12000 \mathrm{~s}$ is observed for the applied potentials. Indeed, for this potential window, the absolute value of the current density is almost constant as expected for a diffusion-limited process. The growth duration drops to $2620 \mathrm{~s}$ at $-0.7 \mathrm{~V}$. This observation is related to an increase of the current density with the applied potential, which is probably due to the growing part of the side reactions. Consequently, coarser and dendritic films are obtained at $-0.7 \mathrm{~V}$.

EDS analysis was used to study the influence of the fixed applied potential on the average composition of the deposits (Figure 7). Surprisingly, all the samples exhibit a ratio $\mathrm{Sn}$ :Se close to 1 , confirming the synthesis of SnSe. Therefore, further analyses were performed in order to have a better understanding of the influence of the applied potential on the deposition mechanism.

\section{XRD analyses}

All samples were analyzed by XRD after transfer. The patterns show the presence of a phase indexed into the orthorhombic structure of SnSe, according to COD 1537675 (Figure 8). This analysis is in good agreement with the chemical composition of the films, which is close to the stoichiometry (Figure 7). The stronger diffraction peak (111) suggests a preferential growth direction whatever the applied fixed potential. Concerning the sample deposited at $0.7 \mathrm{~V}$, weak diffraction peaks are present, confirming the observed low crystallinity from SEM images (Figure 5).

\section{Mössbauer analyses}

To get the oxidation degrees of tin species deposited, ${ }^{119} \mathrm{Sn}$ Mössbauer spectroscopy characterization was performed at room temperature. It should be underlined that Mossbauer spectroscopy analysis was unsuccessful for the samples obtained at $-0.4 \mathrm{~V}$ and $-0.45 \mathrm{~V}$ due to the low amount of deposits. From this analysis, we can conclude that the applied potentials of $-0.4 \mathrm{~V}$ and $-0.45 \mathrm{~V}$ results in deposits of $\mathrm{SnSe}$, with detrimentally low growth rate, weak crystallinity, and inhomogeneous surface.

For the other samples, except those obtained at $-0.7 \mathrm{~V}$, the spectra of deposits show a doublet at an isomer shift of $3.4 \mathrm{~mm} \cdot \mathrm{s}^{-1}$ (Figure 9). This doublet indicates the presence of $\mathrm{Sn}$ (II) in the samples, in agreement with SnSe. The asymmetry of this doublet can be explained by a preferential orientation, as seen on the XRD patterns. Moreover, the quadrupolar splitting is comprised between 0.75 and $0.8 \mathrm{~mm} \cdot \mathrm{s}^{-1}$ for the considered samples. This slight difference indicates no significant change in symmetry or chemical environment. Surprisingly, a weak singlet is also visible at an isomer shift between 0.13 to $0.4 \mathrm{~mm} \cdot \mathrm{s}^{-1}$. This signal reveals the presence of $\mathrm{Sn}(\mathrm{IV})$ in low quantities. From the work of Bernardes-Silva et al., $\mathrm{SnO}_{2}$ should display a peak at about $0.07 \mathrm{~mm} \cdot \mathrm{s}^{-1}\left[{ }^{46}\right]$, which is noticeably different from what we observe in this work. Since the isomer shift is a function of the chemical environment, the presence of $\mathrm{Sn}(\mathrm{IV})$ could be explained by the presence of another compound, such as $\mathrm{SnSe}_{2}$. This result could be explained by the hypothesis of the generation of $\mathrm{Sn}(\mathrm{IV})$ in the electrolyte solution 
De Vos, M., Danine, A., Adam, L., Diliberto, S., Caballero-Calero, O., Martín-González, M., ... \& Stein, N. (2020). Electrodeposition of Tin Selenide from Oxalate-Based Aqueous Solution. Journal of the Electrochemical Society, 167(16), 162502.

Doi: 10.1149/1945-7111/abcb74

due to the instability of $\mathrm{Sn}$ (II) according to Equation 6. Consequently, $\mathrm{SnSe}_{2}$ could be then obtained by considering the following side reaction:

$\mathrm{SnO}_{2}+2 \mathrm{H}_{2} \mathrm{SeO}_{3}+12 e^{-}+12 \mathrm{H}^{+} \rightarrow 8 \mathrm{H}_{2} \mathrm{O}+\mathrm{SnSe}_{2}$ Equation 14

This hypothesis on the presence of $\mathrm{SnSe}_{2}$ agrees, within the accuracy of the measurements, with the observation of a very slight excess of Se for some potentials (Figure 7).Additional characterizations were then realized to identify all the species in the films (see below).

The spectrum of the sample obtained at $-0.7 \mathrm{~V}$ is noisy but typical from Tin $\left(\operatorname{Sn}^{0}\right)$, with a singlet at an isomer shift of $2.5 \mathrm{~mm} \cdot \mathrm{s}^{-1}$ (Figure 9). The presence of Tin confirms the assignment of the peak $\mathrm{C} 1$ " to the cathodic reduction of $\mathrm{Sn}(\mathrm{II})$ to $\mathrm{Sn}^{0}$. Since the corresponding XRD pattern exhibits no diffraction peaks of a phase from Sn (Figure 7), we deduce that amorphous $\mathrm{Sn}^{0}$ is deposited. It should be noticed that EDS analysis show that the atomic ratio $\mathrm{Sn} / \mathrm{Se}$ is equal to 1 at $-0.7 \mathrm{~V}$. Therefore, for this applied potential. we suspect also the presence of amorphous $\mathrm{Se}^{\circ}$ in the film according to the equation 12 .

By considering the weak crystallinity and the presence of various phases, the films obtained at the applied potential of $-0.7 \mathrm{~V}$ are not suitable for any applications. Indeed, structural heterogeneity and highly irregular electron scattering may probably corrupt the transport properties.

\section{Raman analyses}

To investigate the possible presence of amorphous species or minor phases at too low concentration to be detected by XRD, Raman spectra were recorded for samples deposited at the same potentials between $-0.4 \mathrm{~V}$ to $-0.7 \mathrm{~V}$. The spectra are quite similar regardless of the applied potential (Figure 10). Two bands, representative of SnSe, are observed at $70 \mathrm{~cm}^{-1}$ and $156 \mathrm{~cm}^{-1}$. They are attributed to the two Ag vibration modes of SnSe. A wideband from 100 to $120 \mathrm{~cm}^{-1}$ seems to be a $B_{3 \mathrm{~g}}$ vibration mode $\left[{ }^{47-49}\right]$. In the same spectral range, another vibration mode coming from $\mathrm{SnSe}_{2}$ at $119 \mathrm{~cm}^{-1}$ can also contribute to the signal $\left.{ }^{50}\right]$. Another one, found at $185 \mathrm{~cm}^{-1}$, is related to the $\mathrm{A}_{1 \mathrm{~g}}$ vibration mode of $\mathrm{SnSe}_{2}\left[{ }^{51}\right]$. This peak assignment reinforces the hypothesis made from the Mössbauer spectroscopy analysis, namely that the deposits are composed of mainly $\mathrm{SnSe}$ with $\mathrm{SnSe}_{2}$ as a minor secondary phase in particular in the potential range of interest $-0.5 \mathrm{~V} /-0.6 \mathrm{~V}$.

\section{Depth profile analyses by SNMS}

Samples were analyzed by SNMS to investigate the homogeneity and the depth composition of the films. Since this technique requires samples with a surface roughness as small as possible, the samples were analyzed after detachment from the substrate. Then, by starting the sputtering process from the substrate side, optimal surface state conditions were obtained. Here we report the semi-quantitative results, for which the calculation was based on the dataset of the sensitivity values. As it can be seen from the measurements as a whole, the samples deposited at $-0.5 \mathrm{~V}$ (Figure $11 \mathrm{a}$ ), $-0.55 \mathrm{~V}$ (Figure $11 \mathrm{~b}$ ), and $-0.6 \mathrm{~V}$ vs $\mathrm{AgCl} / \mathrm{Ag}$ (Figure $11 \mathrm{c}$ ) are similar in what concerns the component distribution versus the thickness. The comparative evolution of oxygen, $\mathrm{Sn}$, and Se allow us the evaluation of the film thicknesses. Thus, the deposits made at $-0.5 \mathrm{~V},-0.55 \mathrm{~V}$, and $-0.6 \mathrm{~V}$ vs $\mathrm{AgCl} / \mathrm{Ag}$ are respectively close to $1 \mu \mathrm{m}, 700 \mathrm{~nm}$, and $900 \mathrm{~nm}$. Considering the thicknesses obtained by SEM, we should expect values between 1.4 and $1.7 \mu \mathrm{m}$. This difference can be explained by the fact that there was probably a loss of matter during the transfer of the deposits. The oxygen signal exhibits higher intensity when beginning the sputtering, which originates from the oxidation due to the exposure to air. The most important information is the parallel evolution of the intensities of $\mathrm{Sn}$ and $\mathrm{Se}$, with a relatively stable ratio. This means that in 
De Vos, M., Danine, A., Adam, L., Diliberto, S., Caballero-Calero, O., Martín-González, M., ... \& Stein, N. (2020). Electrodeposition of Tin Selenide from Oxalate-Based Aqueous Solution. Journal of the Electrochemical Society, 167(16), 162502.

Doi: 10.1149/1945-7111/abcb74

terms of $\mathrm{Sn}$ and $\mathrm{Se}$, the deposits are homogeneous along the growth direction. The sample deposited at $-0.6 \mathrm{~V}$ vs $\mathrm{AgCl} / \mathrm{Ag}$ seems to be less homogeneous than the others, as expected from its rougher morphology.

\section{Conclusions}

The general objective of this work was to demonstrate the feasibility of the electrodeposition of SnSe films by using sodium oxalate. The electrochemical study highlights the chelating character of the oxalate ions towards Sn(II), improving the stability of the solution. A narrow potential window was defined, between $-0.6 \mathrm{~V}$ to $-0.5 \mathrm{~V}$, leading to the synthesis of a polycrystalline film. The composition of the deposits was found to be homogeneous along the growth direction and close to the stoichiometry, despite a slight excess of selenium, which decreases with the potential. This small deviation is related to the presence of a second minor phase $\mathrm{SnSe}_{2}$, which can be explained by the presence of residual undesired $\mathrm{Sn}(\mathrm{IV})$ cations in the bath. These synthesis results may pave the way for low-cost and environmentally friendly development of functional SnSe films in the broad field of microelectronics.

\section{Acknowledgments}

The authors thank Dr S. Michel (Université de Lorraine) for carrying out ICP-AES analysis. This work was supported by the French National Research Agency and the Swiss National Science Foundation through the ANR project "3D-ThermoNano" (grants ANR-17-CE050027 and 200021E-175703/1). The authors also thank for funding MDV travel grants the French PIA project "LUE" (Grant ANR-15-IDEX-04-LUE) and the COST Action "e-minds" MP1407. MSMS wants to acknowledge the project MAT2017-86450-C4-3-R and Intramural 2D-MESES 201950E057. OCC wants to acknowledge the project I-LINK1231 from CSIC ILINK2017. 
De Vos, M., Danine, A., Adam, L., Diliberto, S., Caballero-Calero, O., Martín-González, M., ... \& Stein, N. (2020). Electrodeposition of Tin Selenide from Oxalate-Based Aqueous Solution. Journal of the Electrochemical Society, 167(16), 162502.

Doi: 10.1149/1945-7111/abcb74

Figure 1: Linear Sweep Voltammetry on the free Sn and Se electrolyte solution performed at $50^{\circ} \mathrm{C}$ with a scan rate of $10 \mathrm{mV} \cdot \mathrm{s}^{-1}$

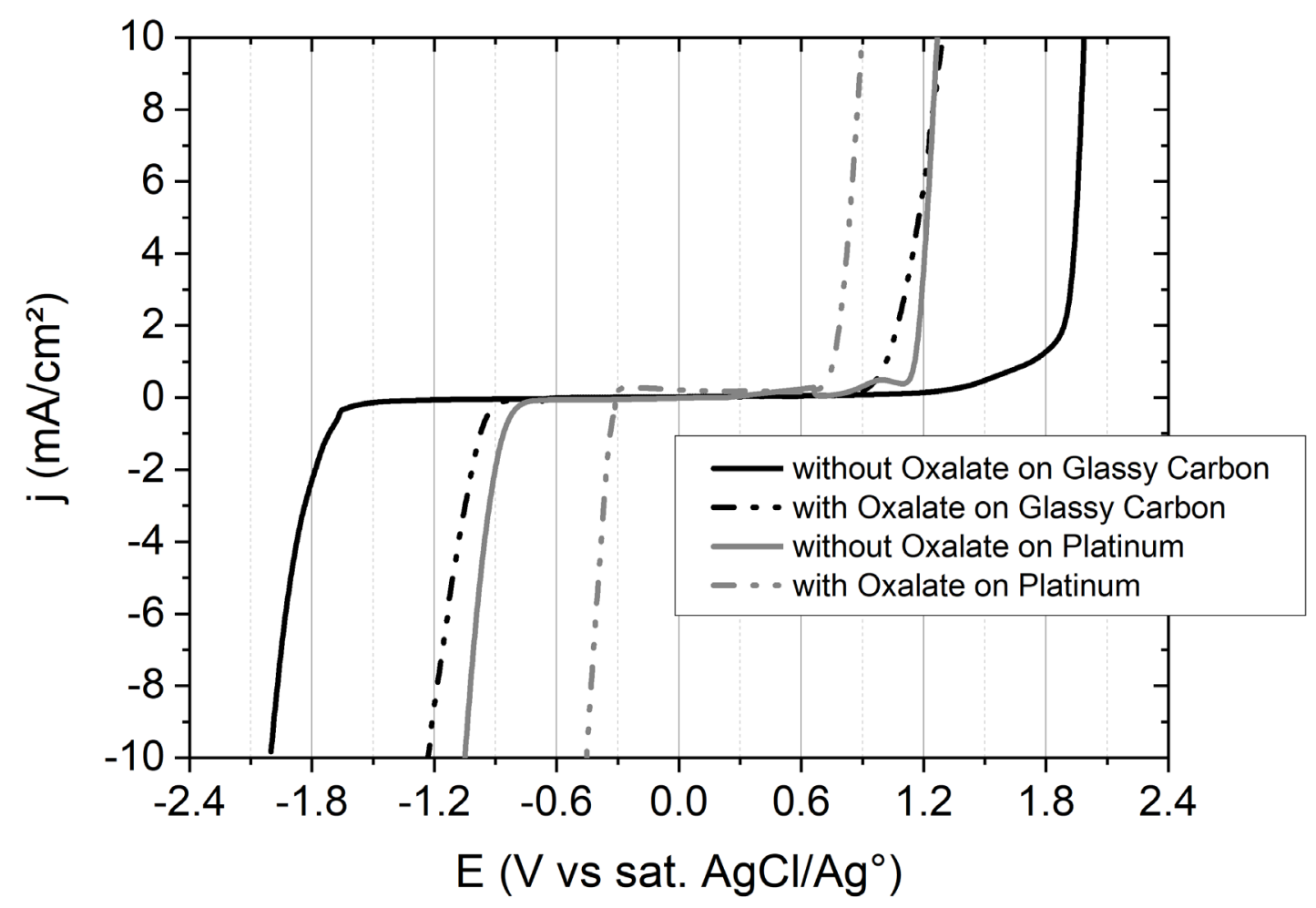


De Vos, M., Danine, A., Adam, L., Diliberto, S., Caballero-Calero, O., Martín-González, M., ... \& Stein, N. (2020). Electrodeposition of Tin Selenide from Oxalate-Based Aqueous Solution. Journal of the Electrochemical Society, 167(16), 162502.

Doi: 10.1149/1945-7111/abcb74

Figure 2: Cyclic voltammetric experiments performed on a $20 \mathrm{mM}$ tin solution at $10 \mathrm{mV} \cdot \mathrm{s}^{-1}$. The potential scan was initiated in the cathodic direction from the OCP. The influence of:

a) temperature, b) oxalate salt, c) age and d) substrate

a

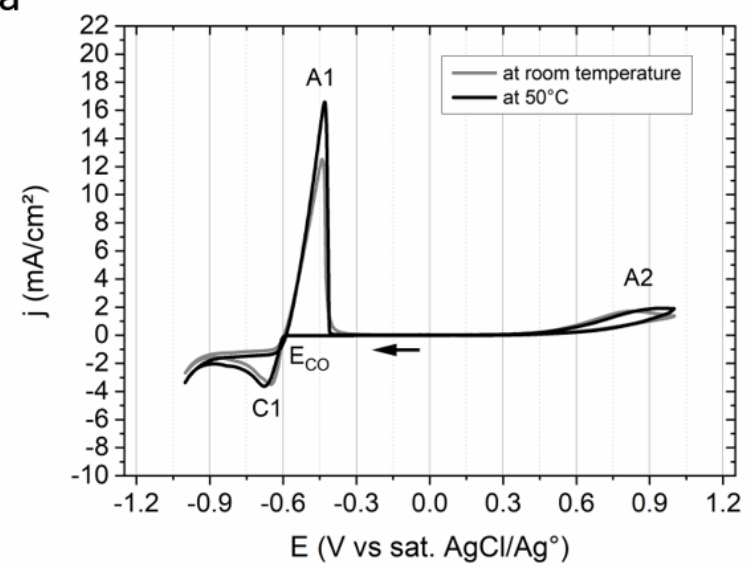

b

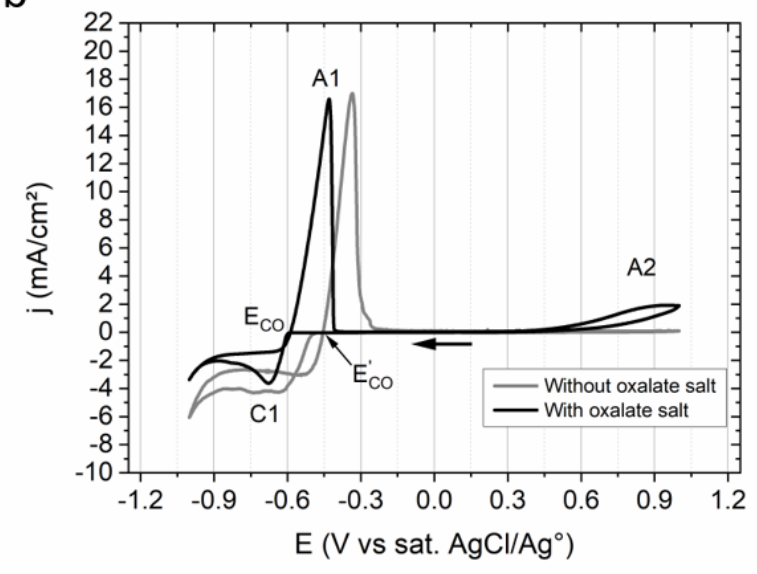

C

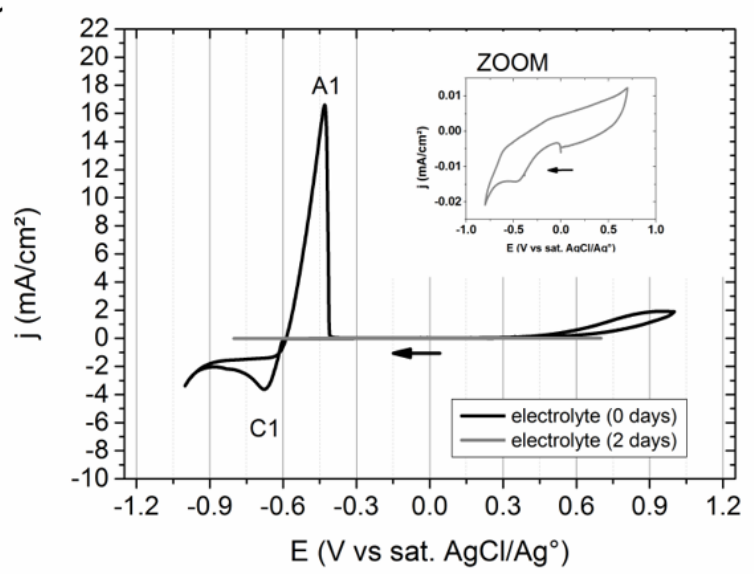

d

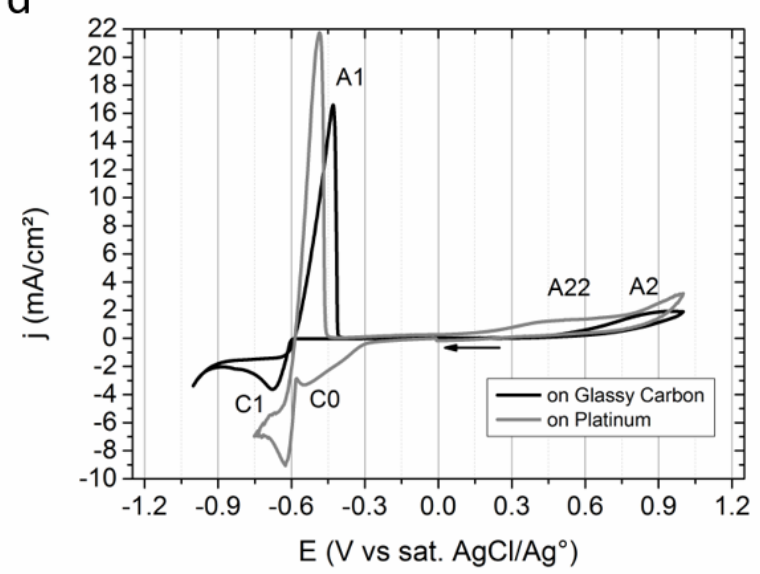


De Vos, M., Danine, A., Adam, L., Diliberto, S., Caballero-Calero, O., Martín-González, M., ... \& Stein, N. (2020). Electrodeposition of Tin Selenide from Oxalate-Based Aqueous Solution. Journal of the Electrochemical Society, 167(16), 162502.

Doi: 10.1149/1945-7111/abcb74

Figure 3: Cyclic voltammetric experiments performed on a $5 \mathrm{mM}$ selenium solution at $10 \mathrm{mV} \cdot \mathrm{s}^{-1}$. The potential scan was initiated in the cathodic direction from the OCP. The influence of:

a) temperature, b) oxalate salt and c) substrate
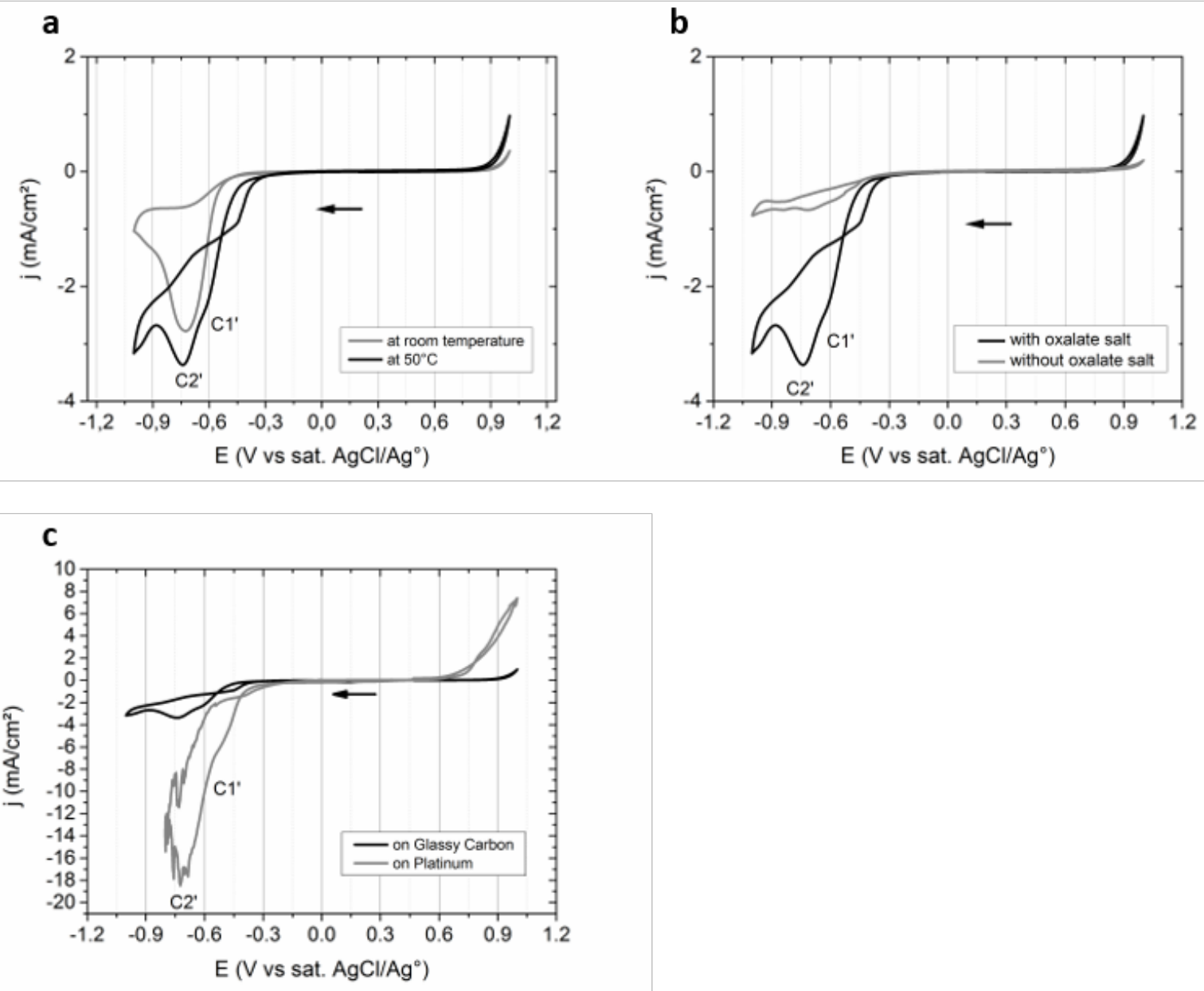
De Vos, M., Danine, A., Adam, L., Diliberto, S., Caballero-Calero, O., Martín-González, M., ... \& Stein, N. (2020). Electrodeposition of Tin Selenide from Oxalate-Based Aqueous Solution. Journal of the Electrochemical Society, 167(16), 162502.

Doi: 10.1149/1945-7111/abcb74

Figure 4: Cyclic voltammetric experiments performed on a $20 \mathrm{mM}$ tin and $5 \mathrm{mM}$ selenium solution at $10 \mathrm{mV} \cdot \mathrm{s}^{-1}$ and $50^{\circ} \mathrm{C}$. The potential scan was initiated in the cathodic direction from the OCP: a) different lower potential and $b$ ) with different pause times

a

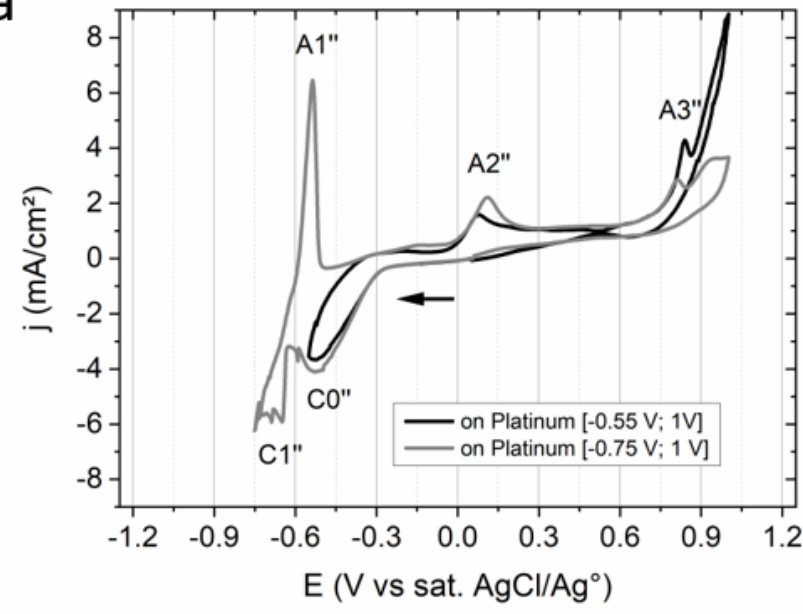

b

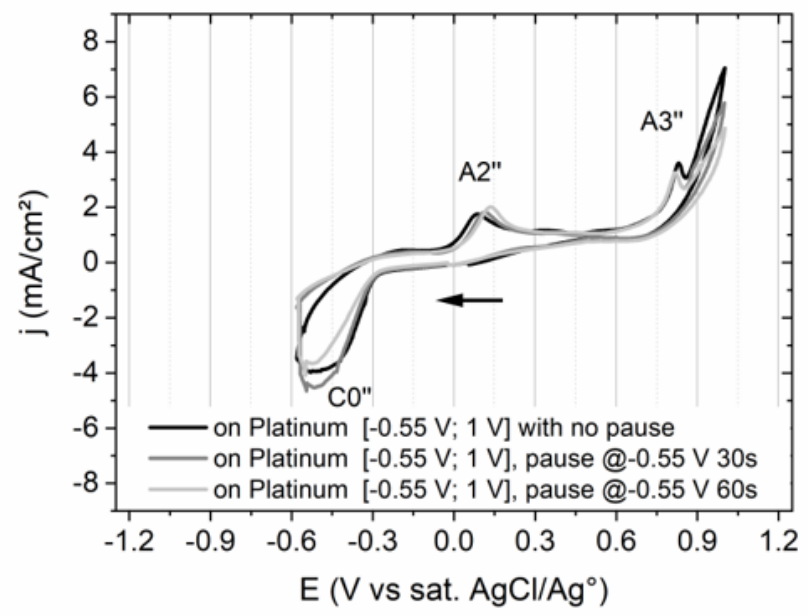


De Vos, M., Danine, A., Adam, L., Diliberto, S., Caballero-Calero, O., Martín-González, M., ... \& Stein, N. (2020). Electrodeposition of Tin Selenide from Oxalate-Based Aqueous Solution. Journal of the Electrochemical Society, 167(16), 162502.

Doi: 10.1149/1945-7111/abcb74

Figure 5: Top face SEM scans of as-deposited samples:

a) $-0.4 \mathrm{~V}, \mathrm{~b})-0.45 \mathrm{~V}, \mathrm{c})-0.5 \mathrm{~V}$, d) $-0.55 \mathrm{~V}, \mathrm{e})-0.6 \mathrm{~V}$ and f) $-0.7 \mathrm{~V}$ vs $\mathrm{AgCl} / \mathrm{Ag}^{\circ}$

a

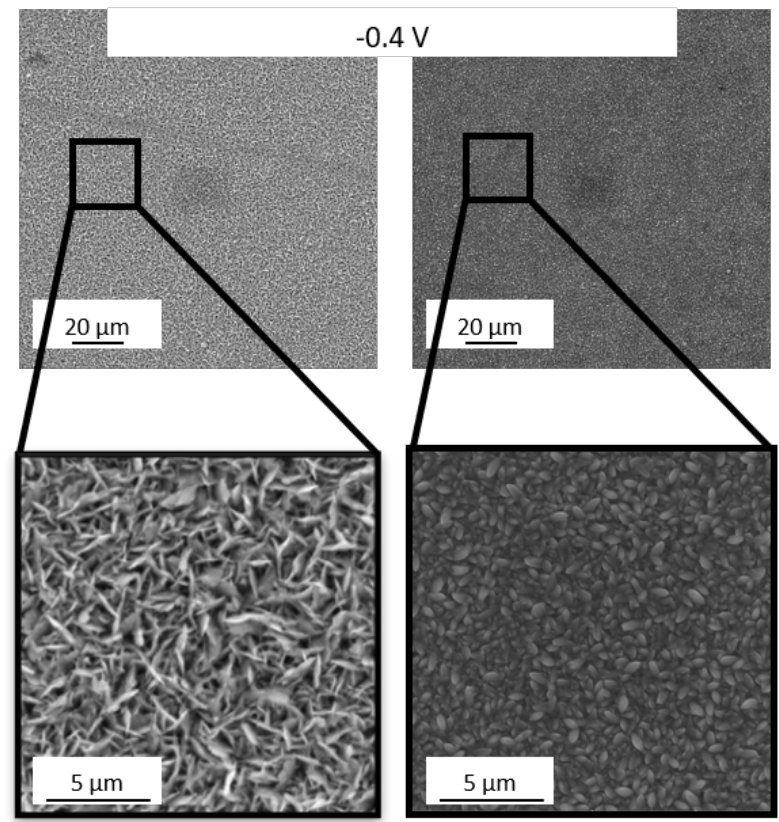

c

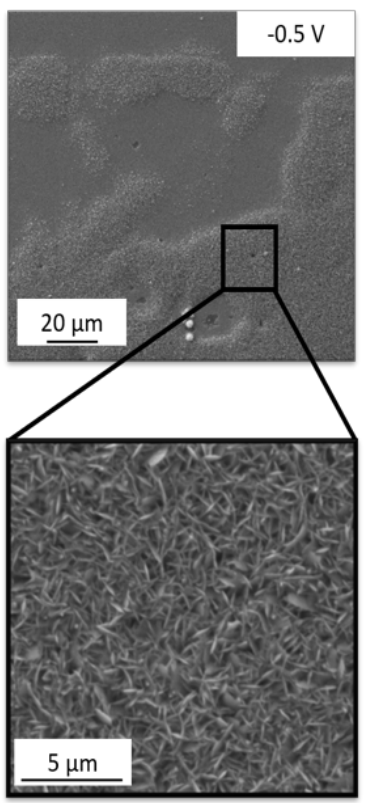

d

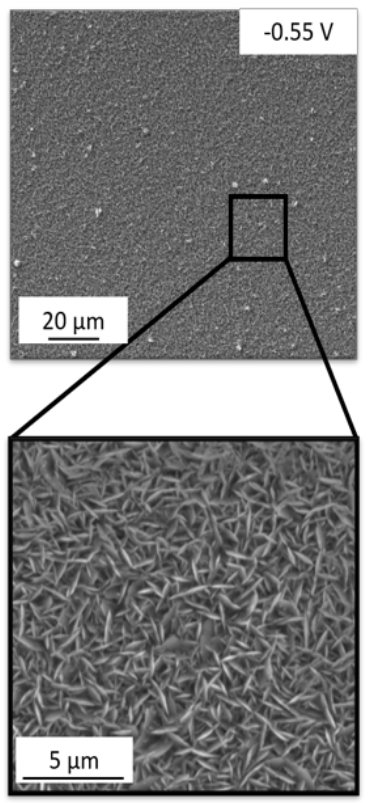

b

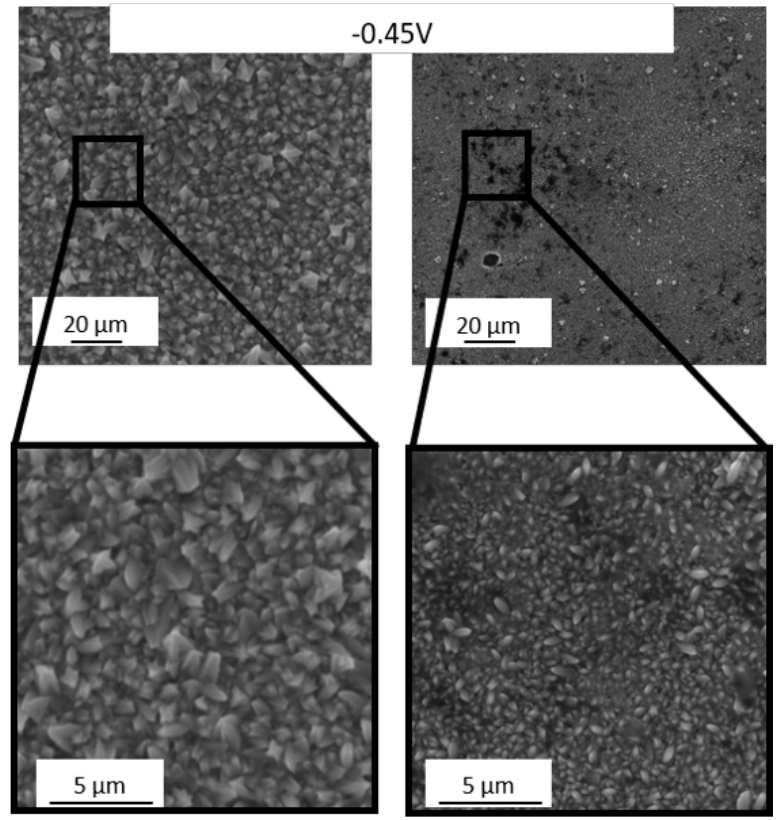

e

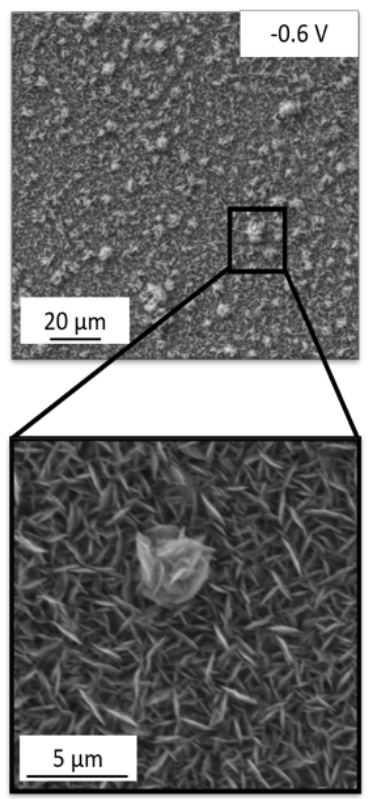

f

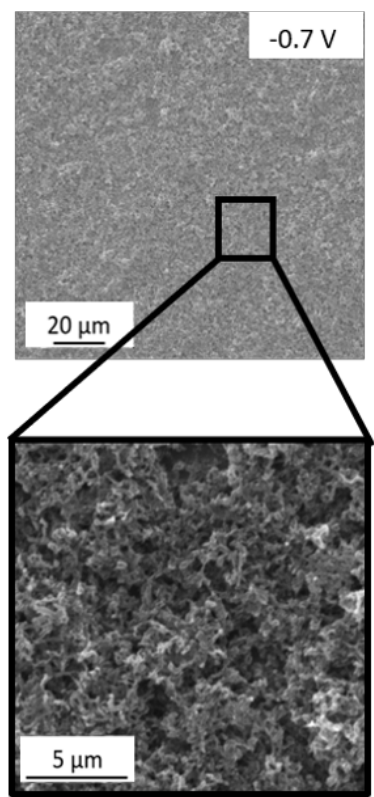


De Vos, M., Danine, A., Adam, L., Diliberto, S., Caballero-Calero, O., Martín-González, M., ... \& Stein, N. (2020). Electrodeposition of Tin Selenide from Oxalate-Based Aqueous Solution. Journal of the Electrochemical Society, 167(16), 162502.

Doi: 10.1149/1945-7111/abcb74

Figure 6: Cross section SEM scans of as-deposited samples:

a) $-0.5 \mathrm{~V}$, b) $-0.55 \mathrm{~V}$ and c) $-0.6 \mathrm{~V}$ vs $\mathrm{AgCl} / \mathrm{Ag}^{\circ}$

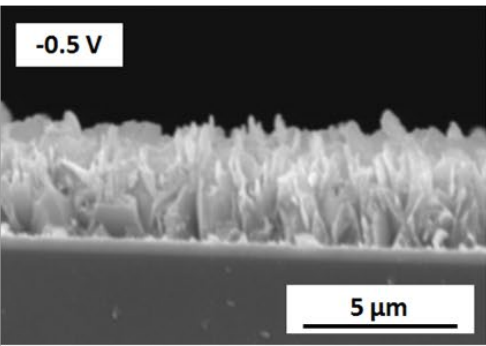

b

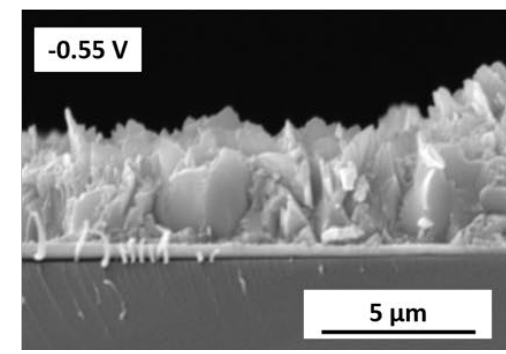

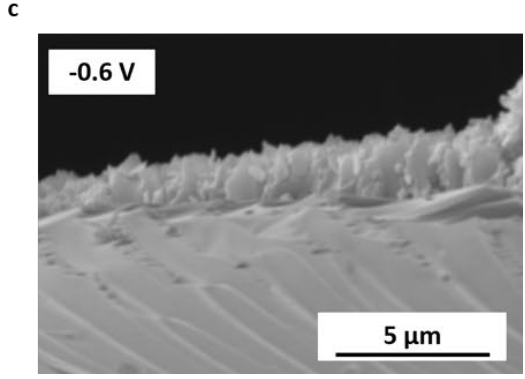


De Vos, M., Danine, A., Adam, L., Diliberto, S., Caballero-Calero, O., Martín-González, M., ... \& Stein, N. (2020). Electrodeposition of Tin Selenide from Oxalate-Based Aqueous Solution. Journal of the Electrochemical Society, 167(16), 162502.

Doi: 10.1149/1945-7111/abcb74

Figure 7: Influence of the deposition potential on the composition (EDS analysis)

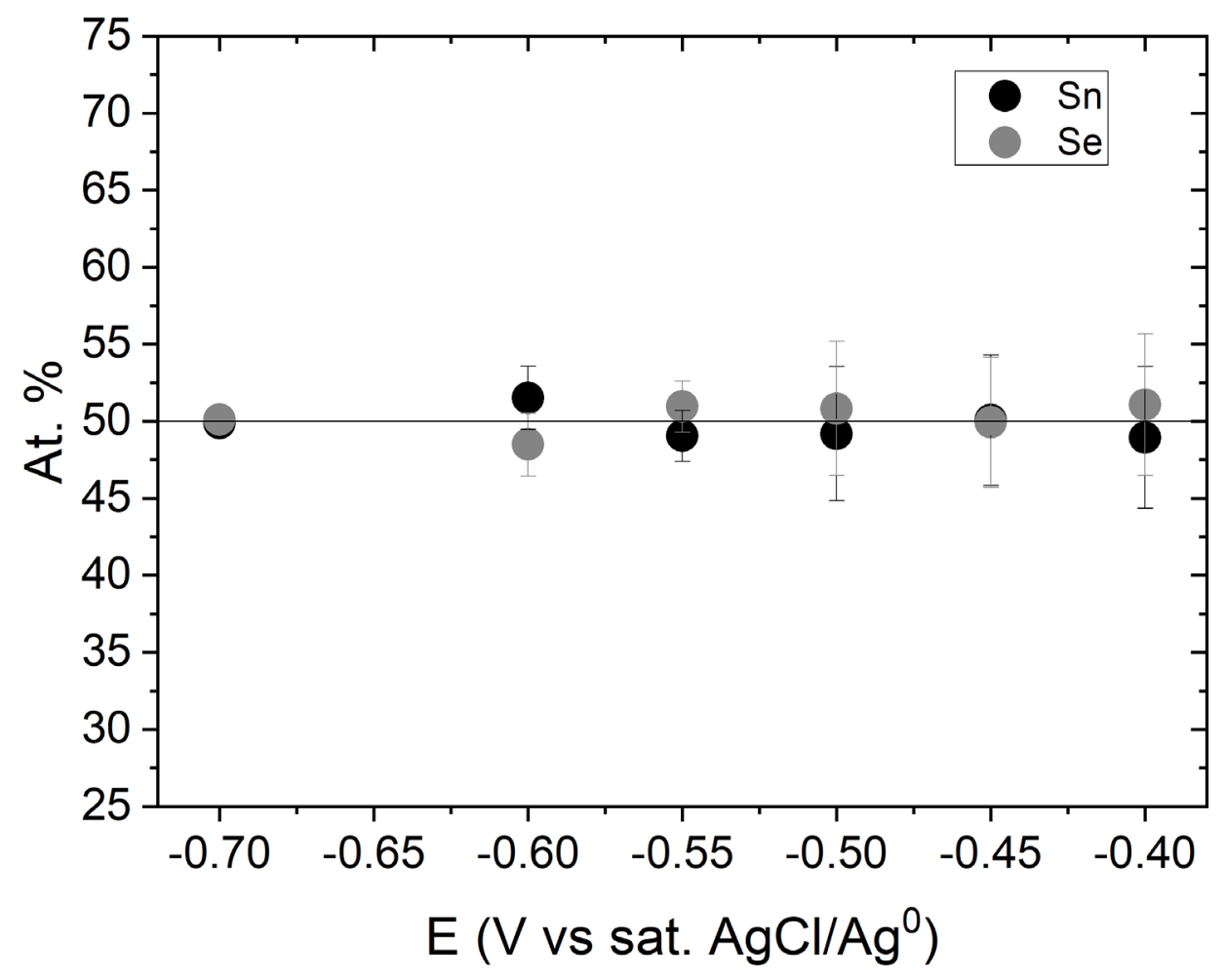


De Vos, M., Danine, A., Adam, L., Diliberto, S., Caballero-Calero, O., Martín-González, M., ... \& Stein, N. (2020). Electrodeposition of Tin Selenide from Oxalate-Based Aqueous Solution. Journal of the Electrochemical Society, 167(16), 162502.

Doi: $10.1149 / 1945-7111 / a b c b 74$

Figure 8: XRD analyses after the transfer of the as-deposited samples

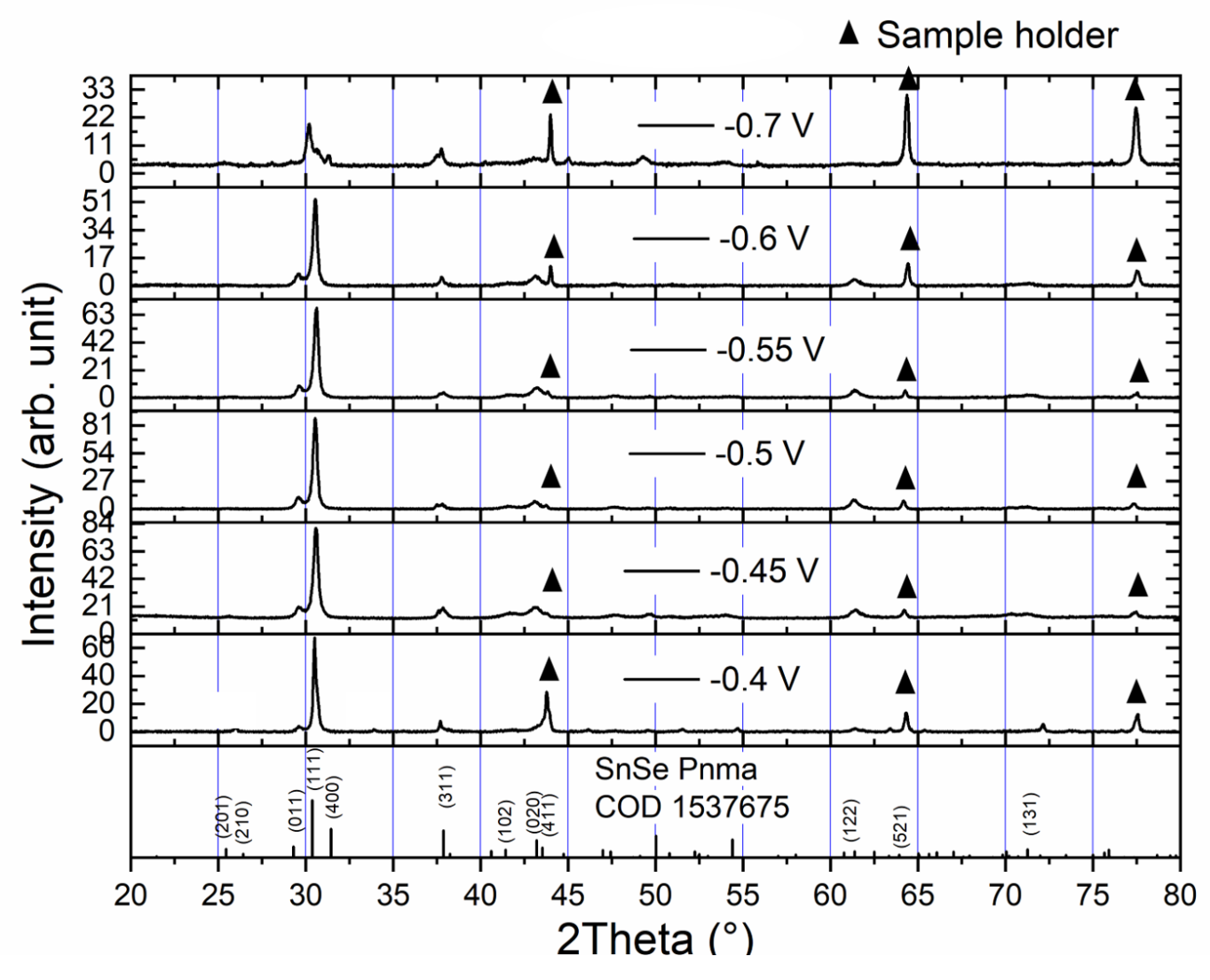


De Vos, M., Danine, A., Adam, L., Diliberto, S., Caballero-Calero, O., Martín-González, M., ... \& Stein, N. (2020). Electrodeposition of Tin Selenide from Oxalate-Based Aqueous Solution. Journal of the Electrochemical Society, 167(16), 162502.

Doi: 10.1149/1945-7111/abcb74

Figure 9: ${ }^{119} \mathrm{Sn}$ Mössbauer spectra performed on the as-deposited samples

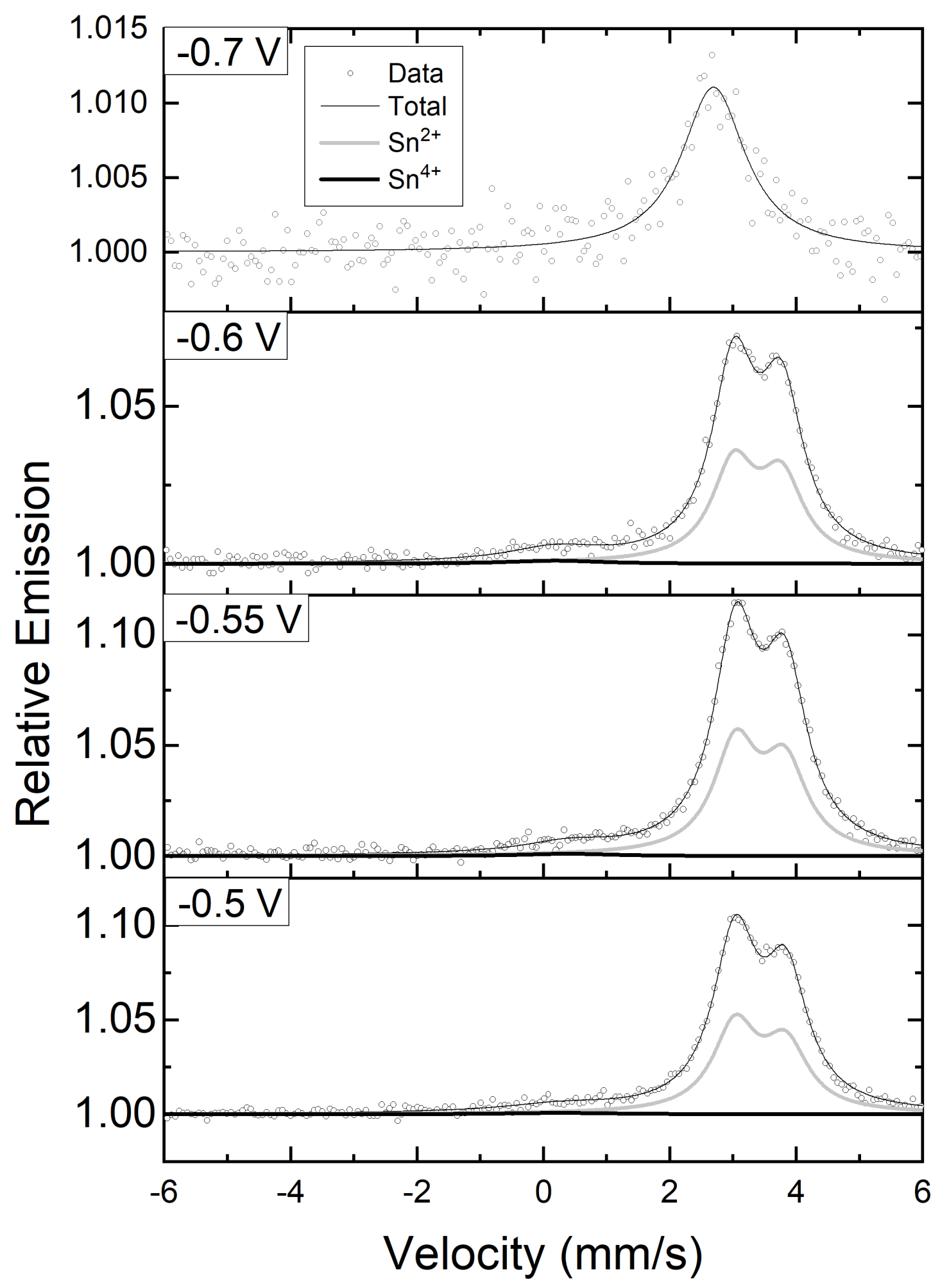


De Vos, M., Danine, A., Adam, L., Diliberto, S., Caballero-Calero, O., Martín-González, M., ... \& Stein, N. (2020). Electrodeposition of Tin Selenide from Oxalate-Based Aqueous Solution. Journal of the Electrochemical Society, 167(16), 162502.

Doi: 10.1149/1945-7111/abcb74

Figure 10: Raman spectra recorded on the as-deposited samples

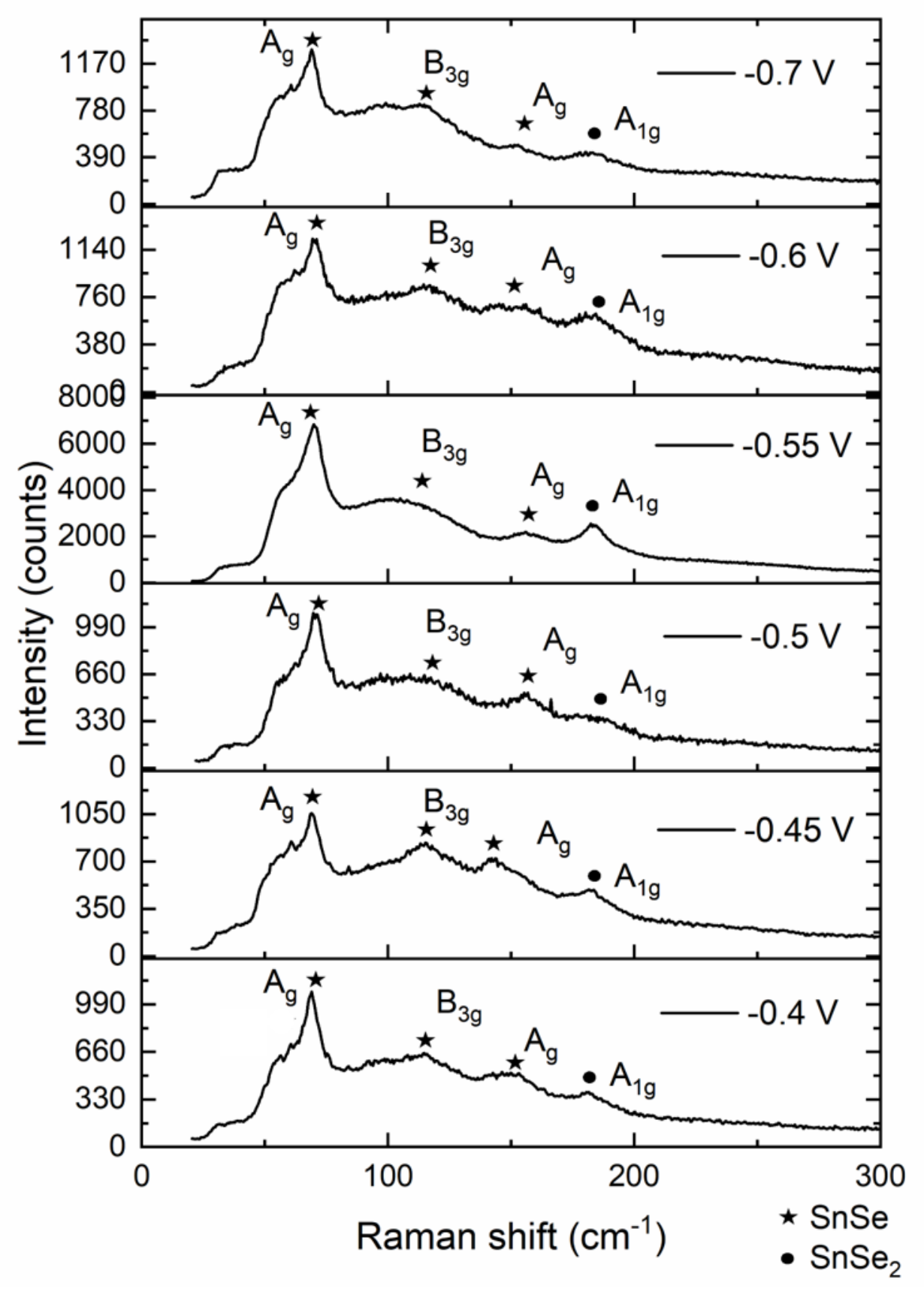


De Vos, M., Danine, A., Adam, L., Diliberto, S., Caballero-Calero, O., Martín-González, M., ... \& Stein, N. (2020). Electrodeposition of Tin Selenide from Oxalate-Based Aqueous Solution. Journal of the Electrochemical Society, 167(16), 162502.

Doi: 10.1149/1945-7111/abcb74

Figure 11: Reverse depth profiles obtained on the as-deposited samples: a) $-0.5 \mathrm{~V}, \mathrm{~b})-0.55 \mathrm{~V}$ and c) $0.6 \mathrm{~V}$ vs $\mathrm{AgCl} / \mathrm{Ag}^{\circ}$

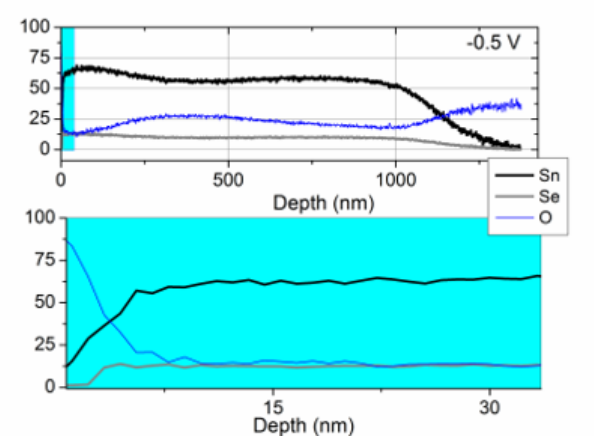

b

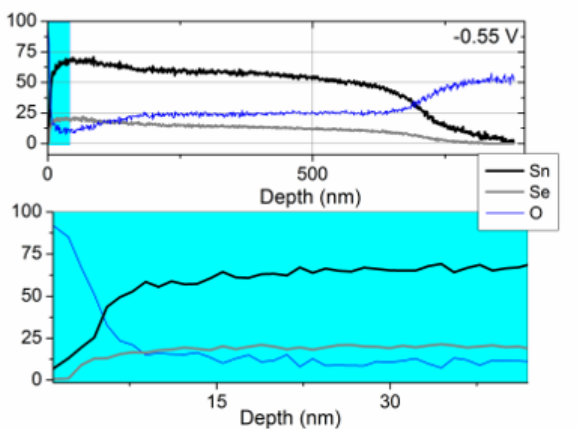

C
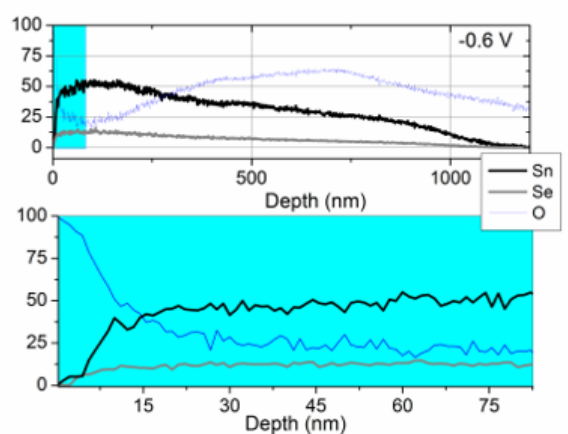
De Vos, M., Danine, A., Adam, L., Diliberto, S., Caballero-Calero, O., Martín-González, M., ... \& Stein, N. (2020). Electrodeposition of Tin Selenide from Oxalate-Based Aqueous Solution. Journal of the Electrochemical Society, 167(16), 162502.

Doi: 10.1149/1945-7111/abcb74

\section{References}

1. V. R. M. Reddy, S. Gedi, B. Pejjai, and C. Park, Journal of Materials Science: Materials in Electronics, 27 (6), 5491-5508 (2016).

2. D. V. Shinde, S.-K. Min, M.-M. Sung, N. K. Shrestha, R. S. Mane, and S.-H. Han, Materials Letters, 115 244-247 (2014).

3. K. J. John, B. Pradeep, and E. Mathai, Journal of Materials Science, 29 (6), 1581-1583 (1994).

4. T.-R. Wei, C.-F. Wu, F. Li, and J.-F. Li, Journal of Materiomics, 4 (4), 304-320 (2018).

5. K. Zweibel, Solar Energy Materials and Solar Cells, 63 (4), 375-386 (2000).

6. K.-M. Chung, D. Wamwangi, M. Woda, M. Wuttig, and W. Bensch, Journal of Applied Physics, 103 (8), 083523 (2008).

7. X. L. Shi, X. Tao, J. Zou, and Z. G. Chen, Advanced Science, 1902923 (2020).

8. W. Shi, M. Gao, J. Wei, J. Gao, C. Fan, E. Ashalley, H. Li, and Z. Wang, Advanced Science, 5 (4), 1700602 (2018).

9. L.-D. Zhao, S.-H. Lo, Y. Zhang, H. Sun, G. Tan, C. Uher, C. Wolverton, V. P. Dravid, and M. G. Kanatzidis, Nature, 508 (7496), 373-377 (2014).

10. L. D. Hicks and M. S. Dresselhaus, Physical Review B, 47 (24), 16631-16634 (1993).

11. M. M. Rojo, B. Abad, C. Manzano, P. Torres, X. Cartoixà, F. Alvarez, and M. M. Gonzalez, Nanoscale, (2017).

12. P. Al-Alam, G. Pernot, M. Isaiev, D. Lacroix, M. De Vos, N. Stein, D. Osenberg, and L. Philippe, Physical Review B, 100 (11), 115304 (2019).

13. M. R. Burton, T. Liu, J. McGettrick, S. Mehraban, J. Baker, A. Pockett, T. Watson, O. Fenwick, and M. J. Carnie, Advanced Materials, 30 (31), 1801357 (2018).

14. S. Anwar, S. Gowthamaraju, B. K. Mishra, S. K. Singh, and A. Shahid, Materials Chemistry and Physics, 153 236-242 (2015).

15. K. S. Urmila, T. A. Namitha, J. Rajani, R. R. Philip, and B. Pradeep, Journal of Semiconductors, 37 (9), 093002 (2016).

16. C. H. Suen, D. Shi, Y. Su, Z. Zhang, C. H. Chan, X. Tang, Y. Li, K. H. Lam, X. Chen, B. L. Huang, X. Y. Zhou, and J.-Y. Dai, Journal of Materiomics, 3 (4), 293-298 (2017).

17. B. Pejova and I. Grozdanov, Thin Solid Films, 515 (13), 5203-5211 (2007).

18. D. Lincot, Thin Solid Films, 487 (1-2), 40-48 (2005).

19. R. Rostek, N. Stein, and C. Boulanger, Journal of Materials Research, 30 (17), 2518-2543 (2015).

20. J.-H. Bahk, H. Fang, K. Yazawa, and A. Shakouri, Journal of Materials Chemistry C, 3 (40), 10362-10374 (2015).

21. R. D. Engelken, A. K. Berry, T. P. Vandoren, J. L. Boone, and A. Shahnazary, Journal of the Electrochemical Society, 133 (3), 581-585 (1986).

22. N. Geoffroy and G. P. Demopoulos, Journal of Chemical Technology \& Biotechnology, 87 (7), 983-989 (2012).

23. N. R. Mathews, Solar Energy, 86 (4), 1010-1016 (2012).

24. B. Subramanian, T. Mahalingam, C. Sanjeeviraja, M. Jayachandran, and M. J. Chockalingam, Thin Solid Films, 357 (2), 119-124 (1999).

25. Z. Zainal, A. J. Ali, A. Kassim, and M. Z. Hussein, Solar Energy Materials and Solar Cells, 79 (2), 125-132 (2003).

26. M. Biçer and i. Şişman, Applied Surface Science, 257 (7), 2944-2949 (2011).

27. A. R. Paris and A. B. Bocarsly, ACS Catalysis, 9 (3), 2324-2333 (2019).

28. L. Maya, Journal of the Less Common Metals, 90 (1), 137-142 (1983).

29. H. Ju, D. Park, and J. Kim, Scientific Reports, 7 (1), 18051 (2017).

30. S. Kim, K. Seong, O. Kim, S. Kim, H. Seo, M. Lee, G. Khang, and D. Lee, Biomacromolecules, 11 (3), 555-560 (2010).

31. S. K. Ghosh, G. Waghoo, A. Kalita, D. Balgude, and K. R. Kumar, Progress in Organic Coatings, 73 (1), 70-75 (2012). 
De Vos, M., Danine, A., Adam, L., Diliberto, S., Caballero-Calero, O., Martín-González, M., ... \& Stein, N. (2020). Electrodeposition of Tin Selenide from Oxalate-Based Aqueous Solution. Journal of the Electrochemical Society, 167(16), 162502.

Doi: 10.1149/1945-7111/abcb74

32. M. R. Burton, C. A. Boyle, T. Liu, J. D. McGettrick, I. Nandhakumar, O. Fenwick, and M. Carnie, ACS Applied Materials \& Interfaces, (2020).

33. K. R. Murali, Journal of Materials Science: Materials in Electronics, 25 (5), 2374-2378 (2014).

34. O. Caballero-Calero, P. Díaz-Chao, B. Abad, C. V. Manzano, M. Ynsa, J. Romero, M. M. Rojo, and M. Martín-González, Electrochimica Acta, 123 117-126 (2014).

35. A. Csik, K. Vad, E. Tóth-Kádár, and L. Péter, Electrochemistry communications, 11 (6), 12891291 (2009).

36. A. Lukinskas, V. Jasulaitienè, P. Lukinskas, I. Savickaja, and P. Kalinauskas, Electrochimica Acta, 51 (27), 6171-6178 (2006).

37. M. Bouroushian, in Electrochemistry of Metal Chalcogenides, p. 57-75, Springer Berlin Heidelberg, Berlin, Heidelberg, (2010).

38. T. Lister and J. Stickney, The Journal of Physical Chemistry, 100 (50), 19568-19576 (1996).

39. T. Lister, B. Huang, R. Herrick, and J. Stickney, Journal of Vacuum Science \& Technology B: Microelectronics and Nanometer Structures Processing, Measurement, and Phenomena, 13 (3), 1268-1273 (1995).

40. Z. Qiao, W. Shang, and C. Wang, Journal of Electroanalytical Chemistry, 576 (1), 171-175 (2005).

41. G. Jarzabek and Z. Kublik, Journal of Electroanalytical Chemistry and Interfacial Electrochemistry, 114 (2), 165-177 (1980).

42. $\quad$ R. Modolo, M. Traore, and O. Vittori, Electrochimica acta, 31 (7), 859-867 (1986).

43. S. Ham, S. Choi, Y. Chae, W. Lee, K.-J. Paeng, W.-G. Kim, and N. Myung, Bulletin of the Korean Chemical Society, 31 (2010).

44. M. Martin-Gonzalez, A. L. Prieto, R. Gronsky, T. Sands, and A. M. Stacy, Journal of the Electrochemical Society, 149 (11), C546-C554 (2002).

45. G. H. Chandra, J. N. Kumar, N. M. Rao, and S. Uthanna, Journal of crystal growth, 306 (1), 6874 (2007).

46. A. C. Bernardes-Silva, A. F. Mesquita, E. d. M. Neto, A. O. Porto, J. D. Ardisson, G. M. d. Lima, and F. S. Lameiras, Materials Research Bulletin, 40 (9), 1497-1505 (2005).

47. H. R. Chandrasekhar, R. G. Humphreys, U. Zwick, and M. Cardona, Physical Review B, 15 (4), 2177-2183 (1977).

48. W. Gao, Y. Li, J. Guo, M. Ni, M. Liao, H. Mo, and J. Li, Nanoscale, 10 (18), 8787-8795 (2018).

49. X.-Z. Li, J. Xia, L. Wang, Y.-Y. Gu, H.-Q. Cheng, and X.-M. Meng, Nanoscale, 9 (38), 1455814564 (2017).

50. P. Fernandes, M. Sousa, P. M. Salome, J. Leitao, and A. Da Cunha, CrystEngComm, 15 (47), 10278-10286 (2013).

51. S. Anwar, S. Gowthamaraju, B. Mishra, S. Singh, and S. Anwar, Materials Chemistry and Physics, 153 236-242 (2015). 